\title{
СМЕРТНОСТЬ ОТ ПОВРЕЖДЕНИЙ С НЕОПРЕДЕЛЕННЫМИ НАМЕРЕНИЯМИ В РОССИИ И В ДРУГИХ СТРАНАХ
}

\section{СЕРГЕЙ ВАСИН}

\begin{abstract}
Смерти от травм и отравлений, которые эксперты не смогли отнести к убийствам, самоубийствам или несчастным случаям, фиксируются в статистике как смерти от повреждений с неопределенными намерениями. Доля таких смертей может свидетельствовать о качестве статистики причин смерти, в первую очередь, статистики умышленных повреждений. В России почти четыре десятилетия кряду смертность от неопределенных намерений теснит смертность от убийств, самоубийств и несчастных случаев. Прежде это наблюдалось в годы повымения смертности от внешних причин, но начавшееся в 2003 г. небывало долгое для России снижение смертности от внешних причин не переломило тенденщию. Вытеснение остальных внешних причин продолжается несмотря на то, что смертность от повреждений с неопределенными намерениями стала выше смертности от убийств и самоубийств, а ее пропориии выросли десятикратно и достигли высоких значений сравнению с другими странами. В отечественных исследованиях последнего десятилетия доказывается, что высокая пропориия смертности от повреждений с неопределенными намерениями - во многом плод манипуляций со статисткой смертности от внешних причин (явления, названного переводом сочииально значимых причин в латентную форму).

В статье на основе сравнения с другими странами и обзора отечественных и зарубежных исследований предпринята попытка расширить контекст и рамки дискуссии, включив в нее вопрос о факторах упорного роста этого «технического» показателя и гипотезах о «естественном» характере такой динамики.
\end{abstract}

Ключевые слова: смертность, Россия, внешние причинь смерти, самоубийства, убийства, повреждения с неопределенными намерениями, неточно обозначенные состояния, качество статистики внешних причин.

\section{1. ВВЕДЕНИЕ}

Намерение (умысел) или «род смерти» - одна из осей классификации внешних причин, по которой они разделяются на три главных блока': а) несчастные случаи - ненамеренные случаи, следствие «стечения обстоятельств»; б) самоповреждения (самоубийства); в) нападения (убийства). Блоки (б) и (в) включают, таким образом, случаи намеренного, умышленного причинения смерти.

СЕРГЕЙ АЛЕКСЕЕВИЧ ВАСИН, ИНСТИТУТ ДЕМОГРАФИИ НАЦИОНАЛЬНОГО ИССЛЕДОВАТЕЛЬСКОГО УНИВЕРСИТЕТА «ВЫСШАЯ ШКОЛА ЭКОНОМИКИ». РОССИЯ.

E-mail: svasin@hse.ru

СТАТЬЯ ПОСТУПИЛА В РЕДАКЦИЮ В СЕНТЯБРЕ 2014 Г.

${ }^{1}$ Помимо них есть еще три блока: Ү35-Ү36 - действия, предусмотренные законом, и военные операции; Ү40Y84 - осложнения терапевтических и хирургических вмешательств; Ү85-Y89 - последствия воздействия внешних причин. Эти блоки вместе с другими блоками случайных повреждений в данной статье мы объединяем в общую группу несчастных случаев. 
Однако на практике встречаются случаи смерти, отнесение которых к одному из трех блоков затруднено, поскольку «доступной информации недостаточно, чтобы медицинские и юридические эксперты могли сделать вывод о том, является ли данный инцидент несчастным случаем, самоповреждением или насилием с целью убийства или нанесения повреждений» [ВОЗ 2003]. Эти случаи относятся к четвертому блоку: повреждения с неопределенными намерениями (далее - ПНН). В странах, где развит институт коронеров, этот блок формируют случаи смерти с открытым вердиктом.

Несмотря на долгую историю существования Международной классификации болезней (МКБ), ПНН как отдельная группа внешних причин появились только в МКБ-8, принятой в 1965 г., и в английском издании дословно называлась «Повреждения, в отношения которых не определено случайно или умышленно они нанесены», а по-русски «Повреждения без уточнения (намерения/умысла)». В отечественной научной литературе до перехода на МКБ-10 употреблялись термины «повреждения без уточнения случайного или преднамеренного характера» и «неуточненные насильственные причины»².

Состав рубрик класса внешних причин смерти определяется механизмом (способом), повлекшим смерть, по этой оси блок ПНН выстроен аналогично другим блокам внешних причин и, более того, идентично блоку самоповреждений (X60-X84). Убийства они же нападения (X85-Y09) - отличаются от них меньшей детализацией способов отравления, а также тем, что имеют свойственные только им рубрики Y04-Y07, в которых в качестве механизмов смерти выступают применение физической силы и разные формы плохого обращения. Сравнение этих трех блоков с блоком несчастных случаев наиболее проблематично, так как классификация последних имеет ряд отличий. Тем не менее для каждой рубрики Y10-Y34 есть «рубрика-тезка» в каждом из основных блоков внешних причин определенного рода, поэтому блок ПНН называют резервуаром ${ }^{3}$ или коллектором случаев смерти из основных блоков внешних причин определенного рода.

Неопределенность, приводящая к отнесению причины смертного случая к ПНН, неизбежна не только из-за дефицита информации об обстоятельствах смерти. «Род смерти не установлен» - «мягкий» по сравнению с другими, например, самоубийством, вердикт, поэтому ПНН пополняют инциденты, о которых известно достаточно много, чтобы подозревать суицид, но недостаточно для того, чтобы преодолеть жесткую планку такого определения. По мнению Ладо Ружички, своим происхождением блок ПНН обязан именно проблеме недоучета самоубийств за счет их неправильной классификации как несчастных случаев [Ruzicka 1996]. «Для регистрации смерти как самоубийства должно быть установлено, что смерть обусловлена неестественными причинами и наступила в результате совершения человеком обдуманного действия с намерением прервать свою жизнь. При возникновении каких-либо сомнений в суицидальных намерениях было весьма вероятно, что смерть регистрировалась как несчастный случай (курсив - наш)» [Ruzicka 1996: 188].

\footnotetext{
${ }^{2}$ В статье термин «насильственная смертность» будет использоваться как синоним смертности от внешних причин.

3 Этот термин принят как в англоязычной, так и в русскоязычной научной литературе.
} 
Введение специального блока причин позволяет улучшить качество статистики смертности от несчастных случаев и оценивать распространенность сомнительных ситуаций. Неслучайно в номенклатурах многих индустриально развитых стран, включая СССР, ПНН присутствовали еще до своего появления в МКБ-8. Вместе с тем переход к МКБ-8 прошел в некоторых странах не гладко: в первые годы после перехода наблюдался внезапный рост числа умерших от ПНН, который сопровождался столь же внезапным падением числа самоубийств [Kolmos 1987; O’Carroll 1989].

Специфика формирования смертности от ПНН задает и специфику ее изучения, в фокус которого попадают уровень и тенденции смертности от ПНН не сами по себе, а в связи с уровнем и тенденциями смертности от внешних причин определенного рода: в первую очередь, если судить по англоязычной литературе, от суицидов и во вторую - от несчастных случаев.

Дискуссия о недоучете самоубийств имеет многолетнюю историю и проливает свет на проблему чрезмерного использования рубрик ПНН в ряде высокоразвитых стран. Общее мнение состоит в том, что самоубийства недоучитываются. Большинство из многочисленных исследований в развитых странах показывают, что помимо случаев смерти, в отношении которых действительно нет достаточной информации («истинных смертей от ПНН»), в этот блок попадают и самоубийства, и несчастные случаи. Процент ошибочных диагнозов варьируется от страны к стране и во времени, а также зависит от типа исследования.

Систематический обзор опубликованных в 1963-2009 гг. исследований достоверности суицидальной статистики на английском и шести других европейских языках, включая три скандинавских, показал, что в 52\% публикаций обнаруженный недоучет составил более $10 \%$, а в 39\% - более 30\% [Tøllefsen, Hem, Ekeberg 2012]. Полнота учета самоубийств зависит от способа суицида: более активные способы (повешение, огнестрельное и холодное оружие) учитываются лучше, чем менее активные (отравления, утопления).

На точность диагностики самоубийств влияют:

- Компетентность судебно-медицинских экспертов или коронеров.

- Процедура и практика судебно-медицинской экспертизы (СМЭ) [Rockett, Kapusta, Bhandari 2011; Chang et al. 2010], в том числе процент судебно-медицинских и патологоанатомических исследований [Kapusta et al. 2011].

- Регламент процедуры соблюдения конфиденциальности, законодательных ограничений и запретов [Rockett, Kapusta, Bhandari 2011].

- Финансовое и кадровое обеспечение [Whitt 2006].

- Религиозный и культурный контекст, т.е. социокультурное порицание [Rockett, Kapusta, Bhandari 2011]. Сюда же можно отнести давление со стороны властей и средств массовой информации [Whitt 2006].

Очевидно, что эти же факторы влияют на частоту обращения судебно-медицинских экспертов к рубрикам блока ПНН. Среди перечисленных выше факторов особое место принадлежит социокультурному порицанию. Этот фактор в отличие от других, тоже 
влияющих на точность диагностики самоубийств, приводит к манипуляции с данными, поскольку эксперт при оценке баланса собранных доказательств под нажимом родственников может отказаться от жесткого вердикта («самоубийство») в пользу мягкого («род смерти не установлен»). В ряде стран из-за культурных и религиозных традиций вердикт «самоубийство» был столь постыдным, что всячески избегался, а то и вовсе был невозможен [Ruzicka 1996: 188]. Социальные и культурные нормы оказывают влияние на формулировку диагноза даже в странах с безупречной статистикой смертности. Так, в Швеции опрос родственников и друзей погибших, а также медиков и изучение свидетельств о смерти позволили установить, что почти две трети всех смертей, закодированных как ПНН, на самом деле были самоубийствами [Horte 1983].

Мотивы, по которым в ПНН могут попадать смерти, в отношении которых есть информация, указывающая, что они произошли в результате убийства, иные: родственники вряд ли заинтересованы в такой подмене диагнозов. Следовательно, под «подозрение» подпадают только инстанции, вовлеченные в процесс установления причины насильственной смерти. В развитых странах в научной литературе эта тема затрагивается крайне редко, что неудивительно. Во-первых, интенсивные исследования недоучета самоубийств сосредоточены на узком круге стран [Tøllefsen, Hem, Ekeberg 2012] с низким уровнем смертности от убийств, а зачастую и от ПНН в целом, поэтому проблема классификации убийств среди ПНН стоит не так остро. Во-вторых, считается, что в демократических странах практика манипуляций со статистикой смертности от убийств не распространена. По другим странам отдельные исследования, посвященные более широкой теме - качеству заполнения медицинского свидетельства о смерти и кодированию первоначальной причины смерти, обнаруживают некоторое число убийств среди неуточненных несчастных случаев и ПНН (см. например, аннотацию статьи [Drumond et al. 1999]). Тем не менее даже в демократических странах проблема недоучета убийств существует, но относится к ранним детским возрастам, в первую очередь к младенческим (см. по США [Sorenson, Shen, Kraus, 1997a, 1997b], по Эстонии [Väli et al. 2007]).

Среди ПНН фигурируют и различные категории несчастных случаев, преимущественно отравления, но также утопления, падения, ДТП и другие.

В проектах ВО3 «Глобальное бремя травматизма» [Begg, Tomijima 2003: 2] и «Глобальные оценки здоровья» [WHO 2014: 4] смерти от ПНН распределены пропорционально среди остальных внешних причин, поскольку смертность от ПНН и ее пропорция по отношению к смертности от других внешних причин - своего рода «технические» индикаторы, характеризующие, пользуясь введенной в одной из недавних публикаций ВО3 метафорой [WHO 2014: 4], «засоренность» статистики внешних причин смерти. Наряду с другими принятыми ВО3 индикаторами ${ }^{4}$, они входят в число показателей качества статистики смертности от других внешних причин смерти. Именно так - не сама по себе, а в контексте других внешних причин - рассматривается смертность от ПНН в зарубежной научной литературе. В России смертность от ПНН достигла масштаба, который компрометирует статистику смертности от внешних причин (прежде всего от таких

\footnotetext{
4 Доля умерших от неуточненных диагнозов и доля случаев, когда место смерти неизвестно, в каждой
} категории внешних причин. 
социально значимых, как убийства, самоубийства, случайные отравления алкоголем) и несомненно заслуживает повышенного внимания.

Цель данной статьи - описать общую картину изменений смертности от ПНН за период с 1956 г., особенно тенденции и ситуацию последних лет, а также исследовать вопрос, насколько необычны достигнутые в России значения «технических» показателей и что стоит за упрямым ростом пропорции смертности от ПНН.

\section{2. ДАННЫЕ И МЕТОД}

Анализ смертности от ПНН и других причин смерти в России за 1956-1998 гг. и в 15 странах с 1965 г. построен на стандартизованных коэффициентах смертности, включая все производные от них показатели (например, структуры смертности), поэтому далее в тексте мы это особо не оговариваем. Данные по причинам смерти, возрасту и полу по России до введения МКБ-10 в 1999 г. - результат реконструкции рядов по причинам смерти [Милле и др. 1996; Meslé et al. 2003], а с 1999 г. - получены из Росстата. Для других стран аналогичные данные об умерших и населении выгружены из базы данных BO3 [WHO Mortality Database] с помощью программы E.M. Андреева [Andreev 2010]. Для анализа рубрик блока Ү10-Y34 по России за 2000-ые годы были использованы неперсонифицированные данные из свидетельств о смерти, которые не являются официальными, но проведенный нами анализ за 2011 г. не выявил существенных расхождений с официальными данными.

\section{3. ОСНОВНЫЕ РЕЗУЛЬТАТЫ}

\section{1. Тенденции смертности от повреждений с неопределенными намерениями}

За последние полвека стандартизованный коэффициент смертности от ПНН в России увеличился в 8 раз у мужчин и в 7 раз у женщин. Следуя в целом тренду смертности от всех, в том числе от остальных внешних причин, изменения протекали неравномерно: периоды снижения и роста чередовались. Весь временной ряд можно разбить на два периода: до и после начала роста смертности от ПНН (конец 1960-х годов у мужчин и середина 1970-х годов у женщин). Во втором периоде с некоторой долей условности можно выделить три отрезка временного ряда: период роста с некоторым снижением в конце периода - до 1990 г.; резкий взлет после 1990 г. с пиком в 1994 г.; последующее снижение, довольно скромное по сравнению с ростом предыдущего периода (рисунок 1). 


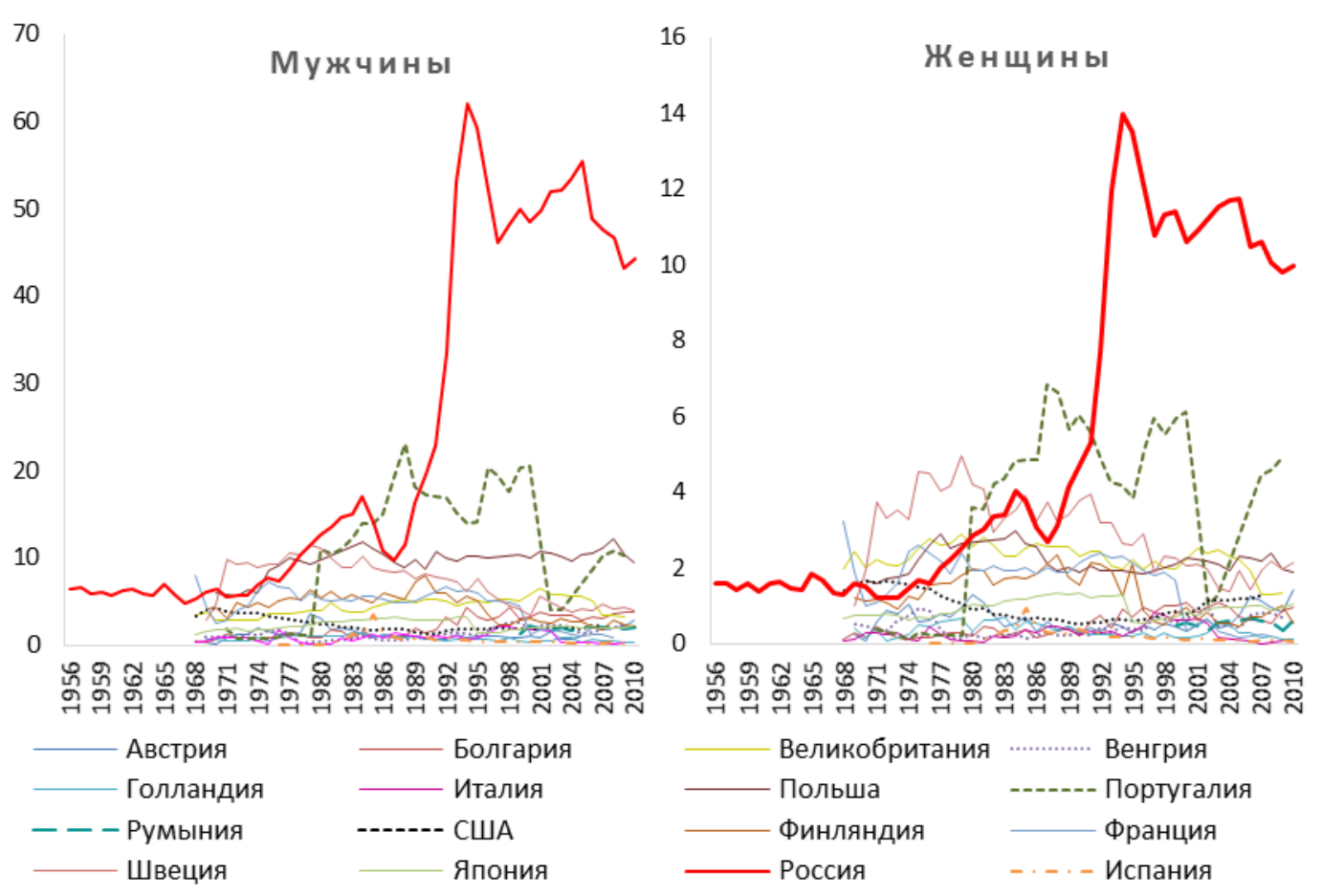

Рисунок 1. Стандартизованный коэффициент смертности от ПНН в России (19562012 гг.) и в 15 странах (конец 1960-х годов - 2010 г.), на 100000

В 1950-е - 1960-е годы показатель имел едва заметную тенденцию к снижению в основном за счет возрастной группы 75 лет и старше (рисунок 2). В этот период на фоне 15 других стран, приведенных на рисунке 1, Россия почти не выделялась. Поскольку смертность от остальных внешних причин в эти годы имела тенденцию к повышению, вклад смертности от ПНН в общую смертность от внешних причин, и без того низкий, уменьшался, в том числе в детских и старших возрастах, в 2 раза и более.

Наступивший затем период изменений смертности от ПНН был неоднороден и подразделяется на несколько этапов, в числе которых и этап снижения в годы антиалкогольной кампании, хотя в целом преобладал рост. Даже в период снижения стандартизованный коэффициент смертности от ПНН в 1987 г. был у мужчин в 1,7 раза, у женщин в 2,2 раза выше, чем в 1973 г. - до начала восходящего тренда. Шестикратный рост показателя с 1987 по 1994 г. изменил ситуацию, приведя к небывалому отрыву от 14 взятых для сопоставления стран и трансформировав возрастные кривые смертности от ПНН: у мужчин возник значительный разрыв в интенсивности смертности между возрастом максимальной смертности (45-59 лет) и остальными возрастами, причем интенсивность смертности в 75 лет и старше стала ниже, чем в возрасте 60-74 года, а та, в свою очередь, ниже, чем в 30-44 года (рисунок 2). У женщин масштаб изменений был меньшим, но и у них более остальных выросла смертность в возрасте 45-59 лет. 


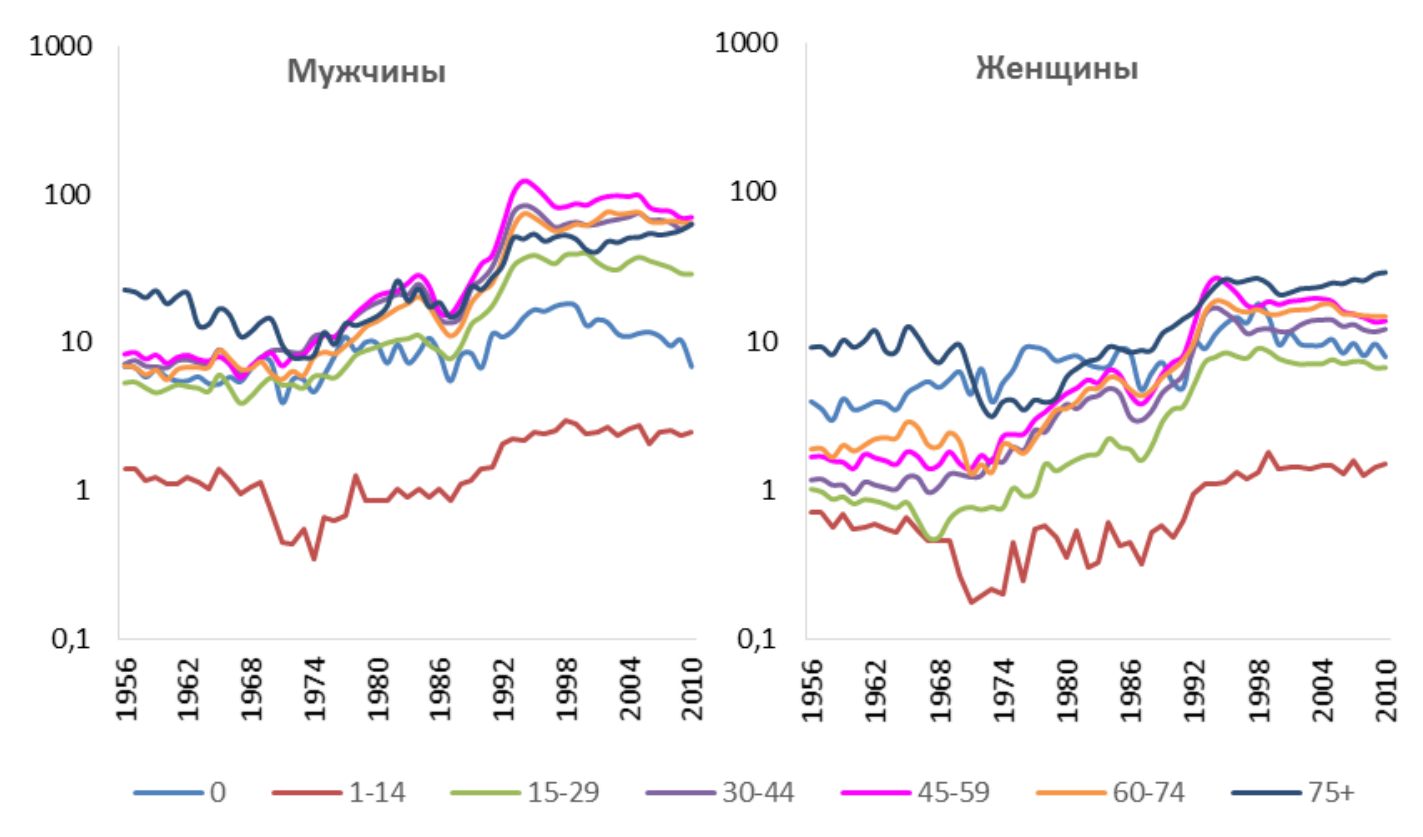

Рисунок 2. Стандартизованные коэффициенты смертности от ПНН в 7 возрастных группах, Россия, 1956-2012 гг., на 100000, логарифмическая шкала

С 1995 г. начался новый этап - неуверенного, с перерывами, снижения смертности от ПНН. К 2012 г. ее уровень отошел от максимума 1994 г., но все ещё многократно выше, чем в большинстве представленных на рисунке 1 стран, и выше значений 1992 г. Более того, в двух возрастных группах смертность от ПНН не снизилась: в 2012 г. она приблизилась (114 лет) и превзошла (75 лет и старше) максимальные за весь период значения (рисунок 2). Впрочем, главная особенность этого этапа - начавшееся с 2003 г. невиданно долгое для России устойчивое снижение смертности от остальных внешних причин, уровень которой вернулся к значениям середины 1960-х годов. А главная проблема в том, что смертность от ПНН теперь в 6-7 раз выше, чем была полвека назад, и ее пропорция в остальных внешних причинах с 2003 г. нарастает (рисунок 3).

\section{2. Пропорция ПНН в смертности от остальных внешних причин в России и в 15 странах}

Отношение стандартизованного коэффициента смертности от ПНН к стандартизованному коэффициенту смертности от остальных внешних причин (на 100), которое для удобства изложения мы назвали «пропорцией ПНН», характеризует качество статистики внешних причин или ее «засоренность», пользуясь введенной экспертами ВО3 метафорой [WHO 2014: 4]. Ухудшение качества статистики с некоторыми перерывами длится с первой половины 1970-х годов. С тех пор показатель вырос в 10 раз, а в большинстве возрастов даже сильнее. Решающий и примерно равный вклад в прирост показателя внесли два периода: 1988-1994 гг. и 2003-2012 гг. Последний вызывает особый интерес.

Зеркальный (по отношению к уровню смертности от остальных внешних причин) рост пропорции ПНН ${ }^{5}$ с 2003 г. - новое явление: раньше при снижении смертности от

\footnotetext{
5 Для краткости далее будем называть это явление: «зеркальный рост пропорции ПНН». 
внешних причин (1985-1987 гг. и 1995-1997 гг.) пропорция ПНН не росла. Напротив, увеличение пропорции ПНН совпадало с увеличением насильственной смертности ${ }^{6}$. Зеркальный рост пропорции ПНН с 2003 г. указывает, что концентрация насильственных смертей в «мусорном» блоке - очень устойчивая тенденция, которая прокладывает себе дорогу и когда смертность от остальных внешних причин растет, и когда снижается.

Закономерно возникают вопросы: что скрывается за столь упорным ростом этого «технического» показателя; насколько обычны его нынешние значения; встречаются ли похожие тенденции в других странах?

Среди 15 сравниваемых стран лишь в Португалии показатель был и остаётся выше, чем в России. Но тренду Португалии, как и Польши в 1970-ые годы, свойственны резкие колебания с очень большими подъемами пропорции ПНН (рисунок 4), причины которых требуют отдельного рассмотрения, хотя огромная амплитуда скачков вызывает недоверие к этим данным.

Для оставшихся стран максимум пропорции ПНН не превышал 19 у мужчин и 18 у женщин, а среднее значение - 5. Для них высокой можно считать пропорцию ПНН чуть выше 10. Такие значения наблюдались довольно долго в Швеции и Великобритании - в странах с надежной статистикой по причинам смерти. К очень высоким можно отнести значения пропорции ПНН свыше 15. Россия достигла отметки 10 в последний год советского периода, а 15 два года спустя. К концу «нулевых» годов Россия превзошла максимальные значения, принадлежавшие Великобритании, а в 2012 г. значения российского показателя стали сопоставимы с португальскими.

Что касается тенденций, восходящий тренд в динамике пропорции ПНН в течение одной-двух декад в разные периоды встречается во многих странах. Точно оценить длительность трендов мешает их неустойчивость, но случаи более длительного подъема показателя среди рассматриваемых стран встречаются редко, а столь же длительные, как в России, не встречаются. К тому же в странах, где тенденция к росту показателя сохранялась две-три декады, его уровень, как правило, оставался весьма умеренным (кроме Великобритании).

\footnotetext{
${ }^{6}$ Исключение составляет резкое падение пропорции ПНН в 1999-2001 гг. на фоне роста смертности от остальных внешних причин, которое, как будет показано ниже, имеет свое специфическое объяснение.
} 


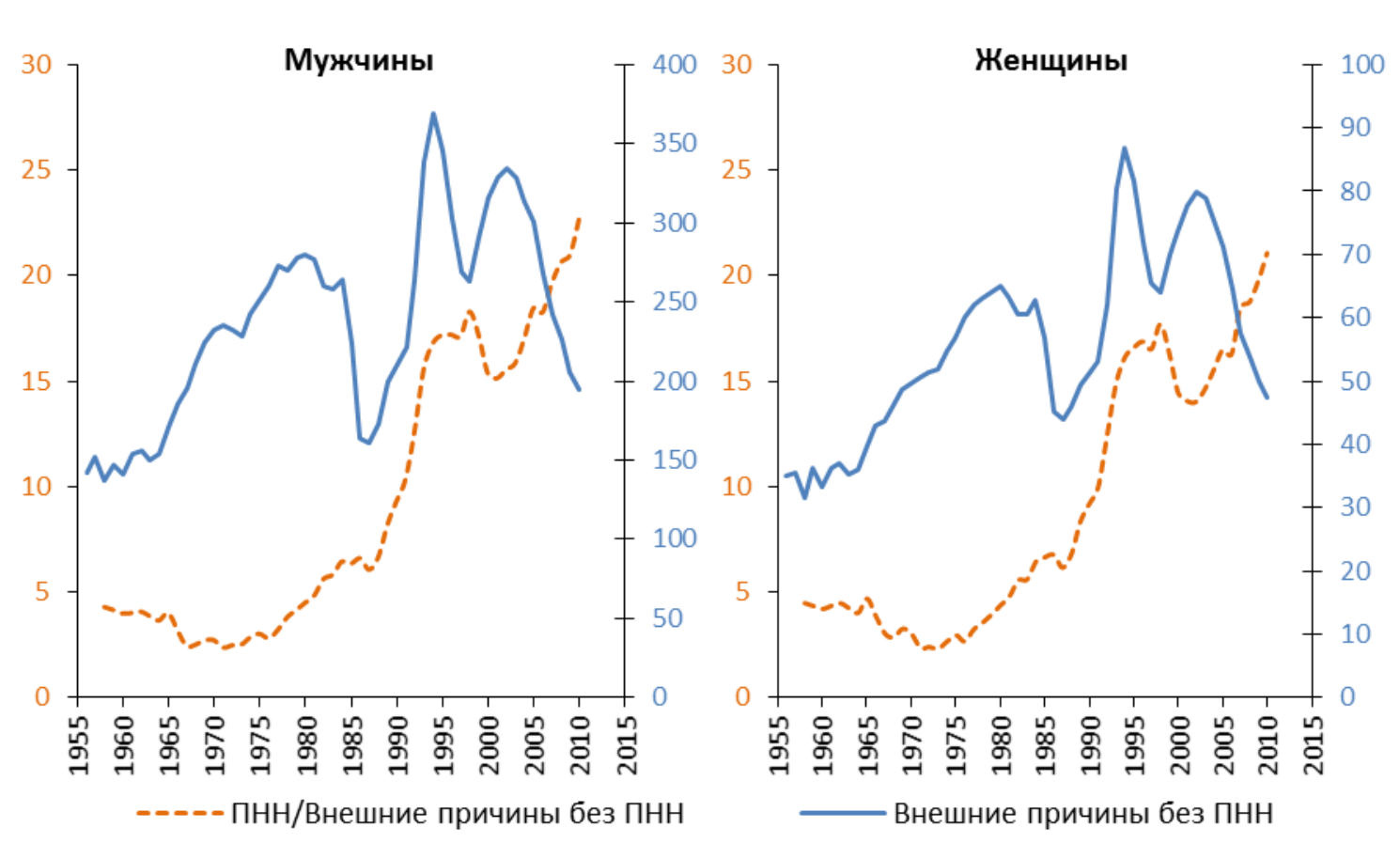

Рисунок 3. Пропорция ПНН на 100 смертей от остальных внешних причин - левая ось и смертность от остальных внешних причин, на 100000 (правая ось)

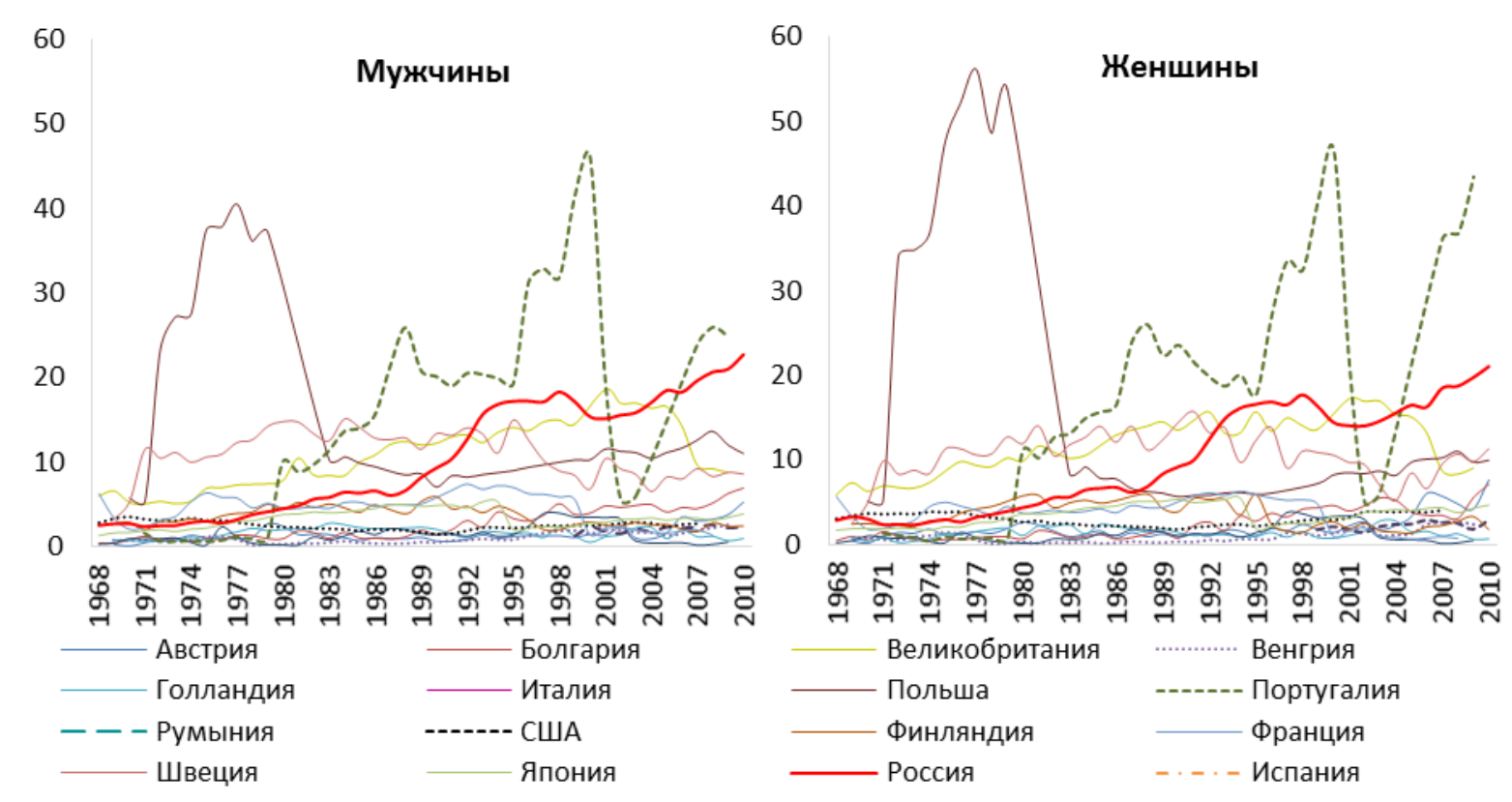

Рисунок 4. Пропорция ПНН на 100 смертей от остальных внешних причин в России и в 14 (без Испании) странах, на 100

Таким образом, Россия на фоне других стран выделяется не столько тенденцией к увеличению пропорции ПНН самой по себе, сколько ее продолжительностью и крайне высоким уровнем показателя.

Пропорция ПНН - мера неопределенности уровня смертности от всех блоков внешних причин, но в зарубежных исследованиях предполагается, что наиболее вероятные 
кандидаты на попадание в число смертей неустановленного рода - самоубийства, и применяется показатель пропорции ПНН / самоубийства ${ }^{7}$.

В России конца 1960-х - начала 1970-х годов смертность от самоубийств в 10 раз превышала тогда еще низкий уровень смертности от ПНН (рисунок 5). Динамика показателя почти повторяет рассмотренную только что динамику пропорции ПНН по отношению к смертности от других внешних причин: соотношение быстро менялось в пользу ПНН и с начала 1990-х годов. Россия вышла на второе место после Португалии, а в последние годы сравнялась с ней. Насколько далеко нынешнее отношение смертности от ПНН к смертности от самоубийств в России от других стран, говорит то, что она в 10-11 раз выше медианы и в 5-6 раз выше значения верхнего квартиля распределения для 15 стран. Только в России (и еще у женщин в Португалии) смертность от ПНН выше, чем от самоубийств.

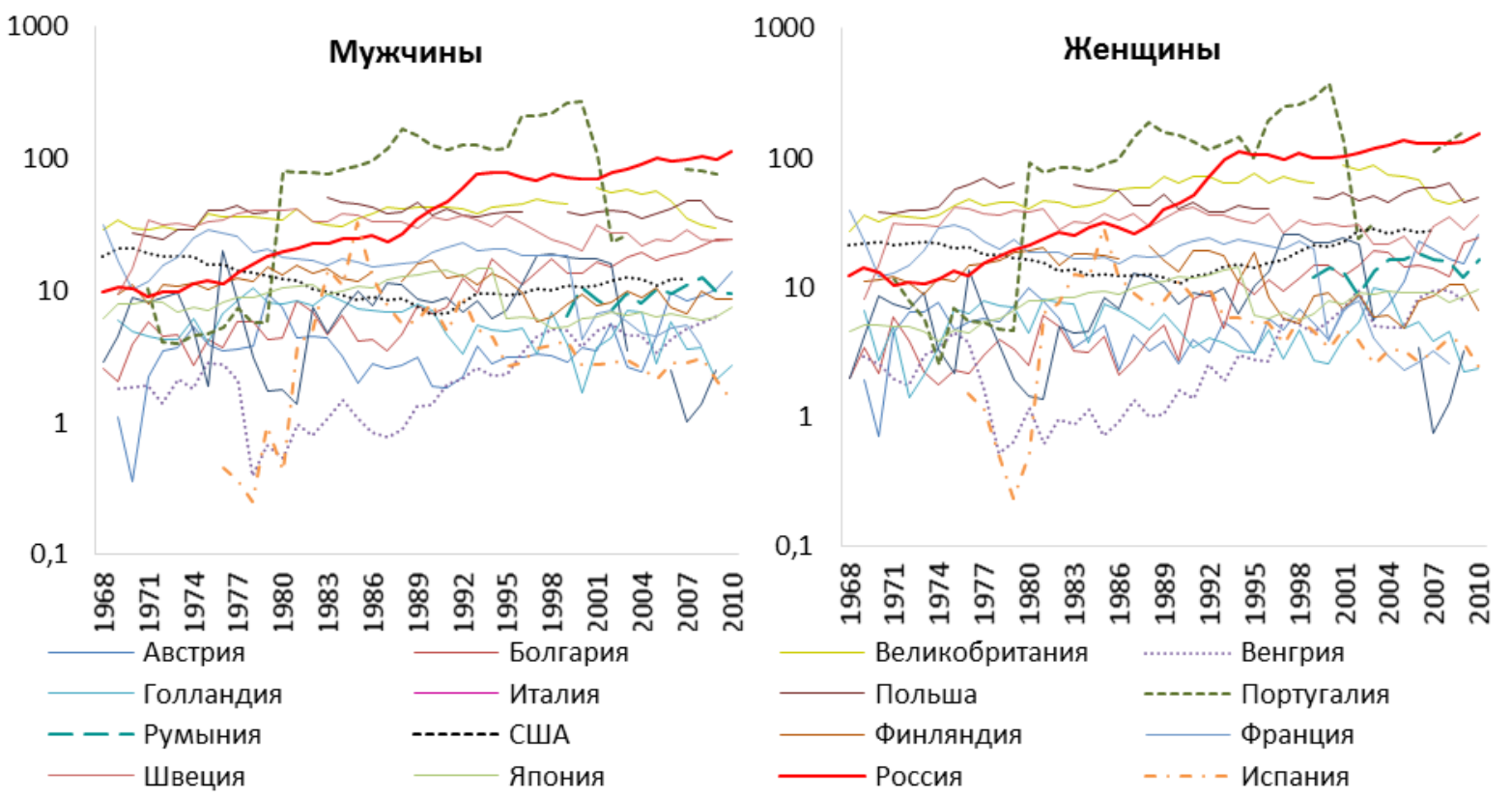

\section{Рисунок 5. Число смертей от ПНН на 100 самоубийств в России и в 15 странах, логарифмическая шкала}

Уровень суицидальной смертности в Португалии, его динамика как сама по себе, так и в сопоставлении со смертностью от ПНН, вызывают сомнение уже давно. В литературе отмечалось, что в 1980-х годах в Португалии значительное число самоубийств кодировалось как ПНН [Castro, Pimenta, Martins 1989], и с тех пор ситуация не изменилась. Поскольку в России соотношение такое же, как в Португалии, под подозрение попадает и полнота учета самоубийств в нашей стране, особенно среди женщин.

Высокий уровень соотношения ПНН/самоубийства наблюдается также в Великобритании, Швеции и Польше. В первых двух странах проблема недоучета суицидальной смертности обсуждается научным сообществом ряд десятилетий, а в Польше - в последние годы [Hofer et al. 2012]. Недавно в качестве ориентира для оценки

\footnotetext{
7 Здесь и далее этот показатель рассчитан как отношение стандартизованных коэффициентов смертности ПНН и самоубийств.
} 
достоверности смертности от самоубийств было предложено использовать уровень смертности от ПНН и его отношение к уровню смертности от самоубийств в странах ЕС-15 [Värnik et al. 2012], которые соответственно равны 2 на 100000 и 20 на 100. Все три упомянутые страны, не говоря уже о России и Португалии, не соответствуют этим критериям качества данных о смертности от самоубийств.

Однако нельзя не признать, что сравнение соотношений смертности от ПНН и самоповреждений уместно для западных стран, но менее уместно для таких стран, как Россия, где большая часть смертей неустановленного рода - это убийства, а не суициды. Неуместность такого подхода для России возникла не сразу, а нарастала вместе с увеличением смертности от нападений, включая ее латентную составляющую, и решающая роль в этом принадлежит периоду 1987-1994 гг.

Еще неуместнее анализировать положение России среди других стран по пропорции ПНН / убийства - оно не выглядит экстраординарным, как в случае с самоубийствами, поскольку смертность от убийств в других странах мала. Например, в шести странах, располагающихся в таблице 1 ниже России, уровень смертности от убийств не просто в 3 10 раз ниже, чем от ПНН, он и сам по себе очень низкий: в 10-50 раз ниже, чем в России. Так что неопределенность оценок смертности от убийств в этих странах - проблема иного порядка.

\section{Таблица 1. Стандартизованные коэффициенты смертности от убийств и соотношение стандартизованных коэффициентов смертности от ПНН и убийств в России и в 15 других странах}

\begin{tabular}{|c|c|c|c|c|c|c|c|c|}
\hline \multirow[b]{3}{*}{ Страна, год } & \multicolumn{4}{|c|}{ ПНН на 100 убийств } & \multicolumn{4}{|c|}{$\begin{array}{l}\text { Стандартизованный коэффициент } \\
\text { смертности от убийств на } 100000\end{array}$} \\
\hline & \multicolumn{2}{|c|}{ отношение } & \multicolumn{2}{|c|}{ ранг } & \multicolumn{2}{|c|}{ коэффициент } & \multicolumn{2}{|c|}{ ранг } \\
\hline & 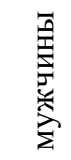 & 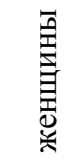 & 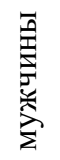 & 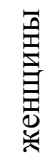 & 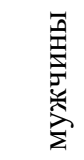 & 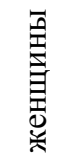 & $\begin{array}{l}\vec{B} \\
\text { 恶 } \\
\text { 帘 }\end{array}$ & 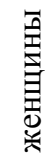 \\
\hline Испания, 2010 & 17 & 12 & 1 & 1 & 0,8 & 0,5 & 13 & 12 \\
\hline Италия, 2009 & 19 & 17 & 2 & 2 & 1,2 & 0,5 & 10 & 13 \\
\hline США, 2007 & 23 & 52 & 3 & 6 & 9,5 & 2,5 & 2 & 2 \\
\hline Голландия, 2010 & 31 & 18 & 4 & 3 & 1,1 & 0,6 & 11 & 7 \\
\hline Румыния, 2010 & 64 & 45 & 5 & 5 & 3,1 & 1,3 & 3 & 3 \\
\hline Финляндия, 2010 & 76 & 64 & 6 & 7 & 2,9 & 0,8 & 4 & 5 \\
\hline Франция, 2008 & 93 & 44 & 7 & 4 & 0,9 & 0,4 & 12 & 14 \\
\hline Венгрия, 2009 & 139 & 71 & 8 & 8 & 1,7 & 1,0 & 6 & 4 \\
\hline Болгария, 2010 & 183 & 140 & 9 & 9 & 2,0 & 0,7 & 5 & 6 \\
\hline Россия, 2010 & 224 & 177 & 10 & 10 & 19,8 & 5,6 & 1 & 1 \\
\hline Швеция, 2010 & 293 & 380 & 11 & 13 & 1,4 & 0,6 & 7 & 8 \\
\hline Япония, 2010 & 632 & 381 & 12 & 14 & 0,4 & 0,3 & 16 & 15 \\
\hline Австрия, 2010 & 667 & 277 & 13 & 11 & 0,4 & 0,5 & 14 & 9 \\
\hline Польша, 2010 & 740 & 374 & 14 & 12 & 1,3 & 0,5 & 9 & 11 \\
\hline Великобритания, 2009 & 760 & 701 & 15 & 15 & 0,4 & 0,2 & 15 & 16 \\
\hline Португалия, 2009 & 765 & 978 & 16 & 16 & 1,3 & 0,5 & 8 & 10 \\
\hline
\end{tabular}

Примечание: Страны ранжированы по величине мужского показателя (столбец 1) в возрастающей последовательности.

Среди 15 стран, пожалуй, только США в чем-то похожи на Россию. Во-первых, по уровню смертности от убийств США идут сразу вслед за Россией с относительно 
небольшим отставанием от нее и с довольно большим отрывом от других стран. Во-вторых, и в США есть довольно большие группы населения с высоким риском смертности от внешних причин. Но США отличает от России то, что пропорция ПНН / убийства ниже, чем в России, в 10 раз у мужчин и в 3,5 раза у женщин. Эта разница дает представление о том, насколько сомнительна статистика смертности от убийств в современной России.

Пролить свет на различия между Россией и США, а также другими странами в источниках формирования смертности от ПНН может сравнение структуры по рубрикам этого блока, приведенное в таблице 2. Поскольку смертность от ПНН в изучаемых странах довольно низка и может быть подвержена случайным колебаниям, по каждой стране, кроме США ${ }^{8}$, были рассчитаны стандартизованные коэффициенты за 4-летний период 2007-2010 гг. Были исключены 5 стран, в которых значения показателя у женщин оказались ниже 0,5 на 100 000. Структура блока ПНН в Португалии отличается от остальных своей простотой: $80 \%$ приходится на самые расплывчатые рубрики (уточненные и неуточненные повреждения), что еще раз указывает на крайне низкое качество статистики внешних причин смерти в этой стране - ниже, чем в России. В США наибольшие затруднения в определении намерения вызывают отравления лекарствами и наркотиками. Похожая картина в Швеции и у женщин в Великобритании. Вообще у женщин удельный вес отравлений лекарствами и суммарно по всем отравлениям значительно выше, что нашло отражение в средней по 8 странам величине. Однако средний профиль в данном случае довольно искусственное построение: разнообразие в подходах к кодированию причин этого блока значительное. В Японии почти $30 \%$ ПНН - утопления, в Болгарии необычно много повешений, а в Венгрии с ее традиционно высокой смертностью от самоубийств структура самая сложная. По-разному задействованы рубрики уточненных и неуточненных повреждений. В Швеции, Австрии, Великобритании и США их используют редко, в Польше, Финляндии и в Болгарии - часто (33-36\%).

По сравнению с другими странами в России отравлений меньше, и среди них преобладают совсем другие виды, а повешений несколько больше. Оба способа смерти, вместе с утоплениями и падениями, гораздо чаще встречаются при самоубийствах, чем при убийствах. Считается [Иванова и др. 2013], что относимые к ПНН смерти, вызванные контактом с острым или тупым предметом, - это убийства, и именно они доминируют в России. Напротив, в 15 странах, несмотря на значительную вариацию в структуре блока ПНН, общим является то, что рубрики Ү28-Ү29 «Контакт с острым и тупым предметом» занимают очень скромное место. Максимум наблюдается в Италии (7\% у мужчин и $11 \%$ у женщин), но в Италии стандартизованный коэффициент смертности от ПНН ничтожно мал: 0,13 и 0,03 на 100000 у мужчин и женщин соответственно.

\footnotetext{
${ }^{8}$ Последние данные по США, по которым можно рассчитать коэффициенты смертности, относятся к 2007 г., но, поскольку население США велико, данные за один год не так подвержены случайным колебаниям, как в других странах со столь же низкой смертностью от ПНН.
} 
Таблица 2. Структура блока ПНН в России (2012 г.), США (2007 г.) и в 8 странах* (2007-2010 гг.), \%

\begin{tabular}{|c|c|c|c|c|c|c|c|}
\hline \multirow[b]{2}{*}{$\begin{array}{l}\text { Коды } \\
\text { МКБ }\end{array}$} & \multirow[b]{2}{*}{ Причина смерти } & \multicolumn{3}{|c|}{ Мужчины } & \multicolumn{3}{|c|}{ Женщины } \\
\hline & & Россия & $\begin{array}{c}8 \\
\text { стран }\end{array}$ & США & Россия & $\begin{array}{c}8 \\
\text { стран }\end{array}$ & США \\
\hline $\begin{array}{l}\text { Y10-Y11, } \\
\text { Y13-Y14 }\end{array}$ & Отравление медикаментами & 1 & 13 & 30 & 3 & 27 & 48 \\
\hline Y12 & Отравление наркотиками НКДР & 2 & 8 & 31 & 1 & 7 & 27 \\
\hline Y15 & Отравление алкоголем & 5 & 3 & 3 & 5 & 3 & 1 \\
\hline Y16-Y19 & Отравления прочие & 10 & 5 & 3 & 14 & 4 & 1 \\
\hline Y20 & Повешение, удушение, удавление & 15 & 10 & 3 & 12 & 7 & 2 \\
\hline Y21 & Утопление & 3 & 14 & 5 & 3 & 13 & 4 \\
\hline Y22-Y24 & Выстрел из огнестрельного оружия & 2 & 3 & 7 & 0 & 1 & 3 \\
\hline Y26 & Дым, огонь и пламя & 3 & 4 & 2 & 3 & 4 & 2 \\
\hline Y28-Y29 & Контакт с острым и тупым предметом & 31 & 3 & 1 & 28 & 3 & 0 \\
\hline Y30 & Падение с высоты & 5 & 9 & 1 & 9 & 8 & 1 \\
\hline Y33-Y34 & $\begin{array}{l}\text { Уточненные и неуточненные } \\
\text { повреждения }\end{array}$ & 20 & 22 & 14 & 19 & 20 & 11 \\
\hline $\begin{array}{l}\text { Y25, Y27, } \\
\text { Y31, Y32 }\end{array}$ & Прочие повреждения & 1 & 6 & 1 & 2 & 4 & 1 \\
\hline Y10-Y34 & Всего & 100 & 100 & 100 & 100 & 100 & 100 \\
\hline
\end{tabular}

По мнению Ивановой и соавторов, в России к убийствам следует отнести и часть смертей от уточненных и неуточненных повреждений (Y33-Ү34) при их сочетании с травмами (рубрики S00-T14, T90-T98). Доля таких случаев в 2012 г. была очень высока: при неуточненных повреждениях - 95\%, при уточненных - примерно $80 \%$. Если руководствоваться классификацией рубрик ПНН, предложенной в статье А.Е. Ивановой и соавторов [Иванова и др. 2013], то совокупно доля убийств в этом блоке (Y22-Y24, Y28Y29 и Y33-Y34 в сочетании с S00-T14, T90-T98) составила в 2012 г. 51\% у мужчин и 45\% у женщин.

Насколько это справедливо для сравниваемых стран, проверить трудно. Однако, если бы это было так, то в той же Португалии, где смертность от таких ПНН в 6-7 раз выше смертности от убийств в 2007-2010 гг., эта проблема, как представляется, не осталась бы без внимания. Но в Португалии обсуждается только недоучет самоубийств. К тому же структура блока ПНН во многом определяется структурой остальных внешних причин. В 12 странах, включая ту же Португалию, смертность от самоубийств выше, чем от убийств, в 7 раз у женщин и в 11 раз у мужчин, тогда как в России - соответственно в 1,2 и в 2 раза (и только у мужчин США это соотношение близко к российскому).

Таким образом, есть все основания полагать, что вклад убийств в формирование смертности от блока рубрик Ү10-Ү34 в рассматриваемых странах невелик, а по сравнению с Россией просто ничтожен. И при этом доля ПНН среди остальных внешних причин в России значительно выше и продолжает увеличиваться.

За исключением уточненных и неуточненных повреждений, свой вклад в нарастание пропорции ПНН в 2003-2012 гг. внесли все рубрики. Наибольший вклад в прирост 
показателя внесли: контакт с тупым и острым предметом (36\% у мужчин и $33 \%$ у женщин), повешение (27 и 21\%), отравления прочие (14 и 17\%) и падения у женщин (14\%). В целом смертность от латентных убийств по сравнению с 2002 г. снизилась в 1,5 раза, а от латентных самоубийств во столько же раз выросла. Соответственно в структуре ПНН вес латентных убийств уменьшился на 15 п.п., а самоубийств увеличился на 10 п.п. К этому привели, главным образом, два обстоятельства: почти двукратный рост смертности от повешений и снижение в 2,3 раза смертности от уточненных и неуточненных повреждений. Последнее свидетельствуют об улучшении качества статистики внутри блока ПНН, ведь рубрики Ү33 и Ү34 - самые расплывчатые, а неуточненные повреждения, по сути, неизвестные внешние причины, так как не определены ни намерение, ни механизм смерти.

\section{3. Смертность от ПНН и от неточно обозначенных причин смерти}

Блок ПНН - не единственный «коллектор» внешних причин смерти. Часть из них, включая смерти от ПНН, могут попадать в класс 18 «Симптомы, признаки, отклонения от нормы, выявленные при клинических и лабораторных исследованиях, не классифицированные в других рубриках» (рубрики R00-R99 по МКБ-10), который тоже был назван «мусорным», но для естественных причин смерти [WHO 2014: 4]. 12 блоков этого класса описывают неясную соматическую патологию, в том числе «Старость» (R54), а последний 13-й блок (R95-R99) «Неточно обозначенные и неизвестные причины смерти» в соответствии с названием включает самые трудные для определения причины смерти инциденты (таблица 3). Для краткости будем ссылаться на этот блок как на «неточно обозначенные и неизвестные причины» $(\mathrm{HOH})$.

Таблица 3. Структура смертности от причин класса 18 МКБ-10 без рубрики R54 («Старость»), Россия, 2012 г., \%

\begin{tabular}{|c|c|c|c|c|c|c|}
\hline \multirow[b]{2}{*}{ Причина смерти } & \multirow[b]{2}{*}{$\begin{array}{l}\text { Код по } \\
\text { МКБ-10 }\end{array}$} & \multicolumn{4}{|c|}{ Возрастная группа } & \multirow[b]{2}{*}{ Всего } \\
\hline & & $\begin{array}{c}0 \\
\text { лет }\end{array}$ & $\begin{array}{l}1-19 \\
\text { лет }\end{array}$ & $\begin{array}{c}20-59 \\
\text { лет }\end{array}$ & $\begin{array}{l}60 \text { лет и } \\
\text { старше }\end{array}$ & \\
\hline езапной смерти & R95 & 65,6 & 0,0 & 0,0 & 0,0 & 0,9 \\
\hline Смерть по неустановленным причинам & R96-R99 & 32,4 & 99,5 & 99,3 & 98,2 & 98,0 \\
\hline $\begin{array}{l}\text { Другие симптомы и неточно } \\
\text { обозначенные состояния }\end{array}$ & $\begin{array}{l}\text { R00-R53, } \\
\text { R55-R94 }\end{array}$ & 2,0 & 0,5 & 0,7 & 1,8 & 1,1 \\
\hline $\begin{array}{l}\text { Все причины класса 18, } \\
\text { кроме R54 («Старость») }\end{array}$ & $\begin{array}{l}\text { R00-R53, } \\
\text { R55-R99 }\end{array}$ & 100,0 & 100,0 & 100,0 & 100,0 & 100,0 \\
\hline
\end{tabular}

Хотя в этот класс должны входить случаи естественной смерти, некоторые смерти, отнесенные к его 13-му блоку, в силу своей необъяснимости или внезапности могут быть вызваны и неестественными причинами. Как было установлено в ряде зарубежных исследований [Värnik et al. 2010; Rockett, Kapusta, Bhandari 2011; Gjertsen, Johansson 2011], сюда действительно попадают и случаи смерти от внешних причин. Для анализа статистики смертности от внешних причин важным является вопрос: случайно или нет это происходит, т.е. порождает ли это систематическое смещение в вариации смертности от внешних причин во времени и в пространстве. За редким исключением [Bjorkenstam et al. 2014] в работах, посвященных анализу достоверности статистики смертности от самоубийств, считается, что недоучет самоубийств неслучаен, отсюда и довольно высокая вероятность 
их отнесения к рубрикам R96-R99. Поэтому в качестве оценки неопределенности уровня смертности от самоубийств при международных сравнениях предлагается использовать отношение смертности от самоубийств не только к смертности от ПНН, но и к смертности от причин, входящих в блок R96-R99 [Rockett, Kapusta, Bhandari 2011].

В России предположение, что часть насильственных смертей находится среди неточно обозначенных причин смерти, высказывалось в нулевые годы [Семенова, Антонова 2007]. В настоящее время гипотеза считается подтвержденной, причем, как и в случае с завышением смертности от ПНН, некоторые исследователи полагают, что это манипуляция, цель которой - завуалировать острую проблему высокого уровня смертности от внешних причин [Иванова и др. 2013].

Так, например, трактуется резкое изменение смертности от ПНН и неточно обозначенных состояний (они поменялись местами) в 1999-2001 гг. в Москве (рисунок 6) [Архангельский и др. 2006; Антонова 2007; Семенова, Антонова 2007; Иванова и др. 2013; Gavrilova et al. 2008]. Понятно, что подобная практика может влиять на динамику регистрируемой насильственной смертности, в частности на соотношение смертности от ПНН и от других внешних причин.

Конечно, не все смерти, попавшие в рубрики неизвестных причин, тем более в старших возрастах, должны относиться к насильственным, а попавшие сюда насильственные смерти должны представлять все группы внешних причин, а не только ПНН. Однако сомневаться в том, что в России в 18-й класс МКБ-10 попадают смерти, которые должны кодироваться в блоке Y10-Y34 (ПНН), тоже нет оснований.

Во-первых, из 13 блоков класса 18, в который входит 99 состояний, фактически используются только 13-й - R96-R99 (в 2012 г. на его долю пришлось более 98\% случаев смерти, таблица 3), а чаще всего - только одна из его рубрик. В регионах России и в 2005 г. [Антонова 2007], и в 2010 г. выбор падает на R99 - самую неточную рубрику, часто сопровождаемую записью «Причина смерти неизвестна» [Иванова и др. 2013].

Во-вторых, по сложившейся в настоящее время практике, процессуальные лица, которые определяют причину насильственной смерти, выносят вердикт «род смерти не установлен», а судебно-медицинские эксперты кодируют его как R99, a не Y10-Y34 [Иванова и др. 2013]. Поэтому неслучайно, что блоки класса 18 заполнены так неравномерно. Соматические рубрики пусты, так как их заполняют врачи, которые следуют рекомендации не злоупотреблять этими рубриками чрезмерно [Руководство ... 2008: 10; КЗ СПб 1997], а 13-й блок полон благодаря судебно-медицинским экспертам. Наконец, отсутствие в динамике смертности от остальных внешних причин слома в 2000 г. (рисунок 6) косвенно подтверждает, что, во всяком случае в Москве, с 2000 г. именно смерти от ППН стали кодироваться как $\mathrm{HOH}$. 


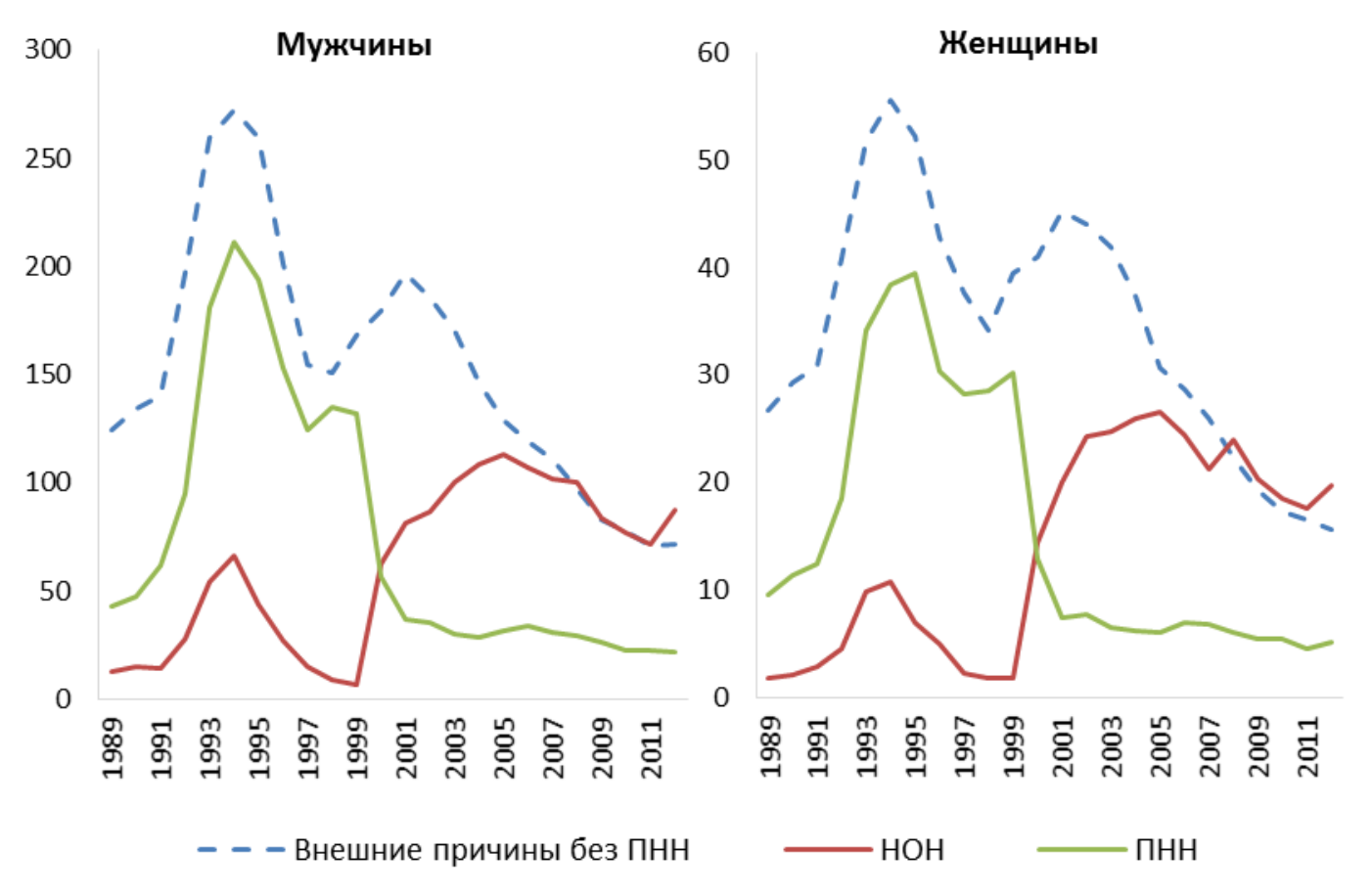

\section{Рисунок 6. Стандартизованные коэффициенты смертности от НОН, ПНН и остальных внешних причин в возрасте 15-59 лет в 1989-2012 гг., Москва, на100000}

Примечание: До 1999 г. сумма всех рубрик класса «Симптомы, признаки и неточно обозначенные состояния» по МКБ-9 (в советской краткой номенклатуре), кроме рубрики «Старость»; после 1999 г. - все рубрики класса 18 МКБ-10 (R00-R53, R55-R94, R96-R99), за исключением R54 («Cтарость») и R95 («Синдром внезапной смерти младенца»); в 2011-2012 г2.: R96-R99.

В России рост смертности от НОН и снижение смертности от ПНН были умереннее, чем в Москве, и начались годом раньше (рисунок 7). Разница в один год может быть связана с тем, что именно в 1999 г. Россия перешла от МКБ-9 к МКБ-10, тогда как Москва - позже [Danilova, Meslé, Vallin 2014]. Иначе говоря, случайно или нет, но изменение в кодировании этих причин совпало с переходом к МКБ-10.

Перевод части смертей из ПНН в $\mathrm{HOH}$ может объяснить «аномальное» снижение пропорции ПНН на фоне роста смертности от остальных внешних причин в 1999-2002 гг., но не объясняет период с 2003 г., когда смертность от остальных внешних причин стала снижаться, а от ПНН продолжала расти еще три года, и вообще наблюдался зеркальный рост пропорции ПНН в 2003-2012 гг. В рамках гипотезы о «переводе» в $\mathrm{HOH}$ насильственных смертей так могло произойти, если бы с 2003 г. переброска диагнозов осуществлялась преимущественно из остальных внешних причин. 


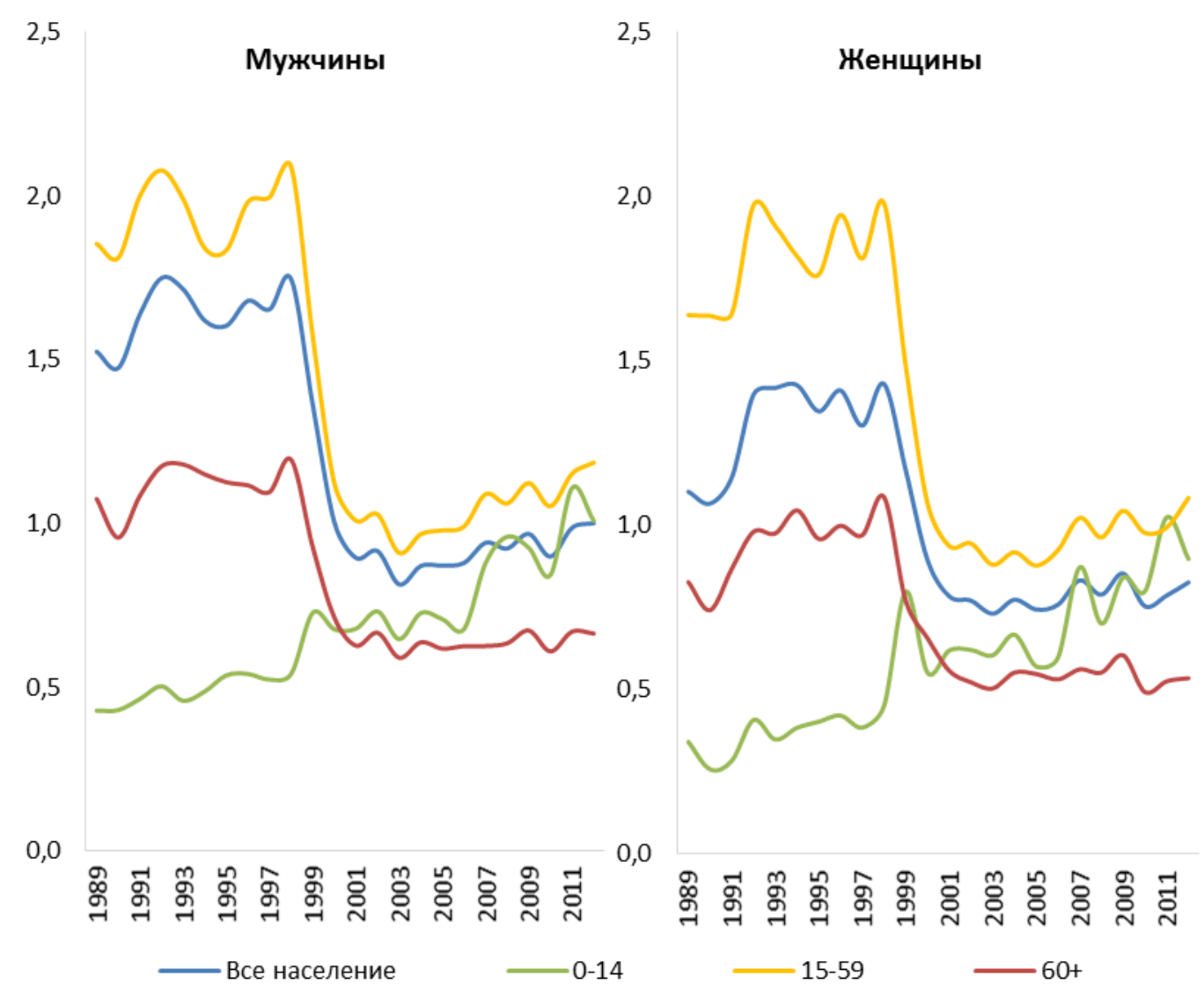

\section{Рисунок 7. Соотношение стандартизованных коэффициентов смертности от ПНН и от НОН (ПНН / НОН) в 1989-2012 гг. по возрастным группам и в населении в целом}

Примечания: а) До 2011 г.: класс 18 иеликом (R00-R53, R55-R94, R96-R99), за исключением R54 («Старость») и R95 («Синдром внезапной смерти младенца»), в 2011-2012 гz.: R96-R99; б) укрупненными маркерами на рисунке отмечен 1999 г. - год перехода на новую краткую номенклатуру причин смерти по МКБ-10.

Как бы то ни было, изменение в кодировании причин в 1999-2001 гг. отразилось на уровне смертности от ПНН и неточно обозначенных состояний, но не на суммарной смертности от обеих причин, которая в эти годы росла быстрее, чем смертность от остальных внешних причин. Устойчивый рост отношения смертности от обеих категорий неопределенных причин к остальным внешним причинам продолжился и в дальнейшем. В результате, как показывает рисунок 8, снижение смертности от случайных повреждений, убийств и самоубийств в последнее десятилетие сопровождается ростом пропорции как ПНН, так и НОН, т.е. еще большей неопределенностью в отношении истинного уровня смертности от внешних причин. Стоит отметить и то, что довольно согласованные изменения смертности от ПНН и НОН после 2000 г. могут свидетельствовать об общих факторах, стоящих за этими изменениями. 


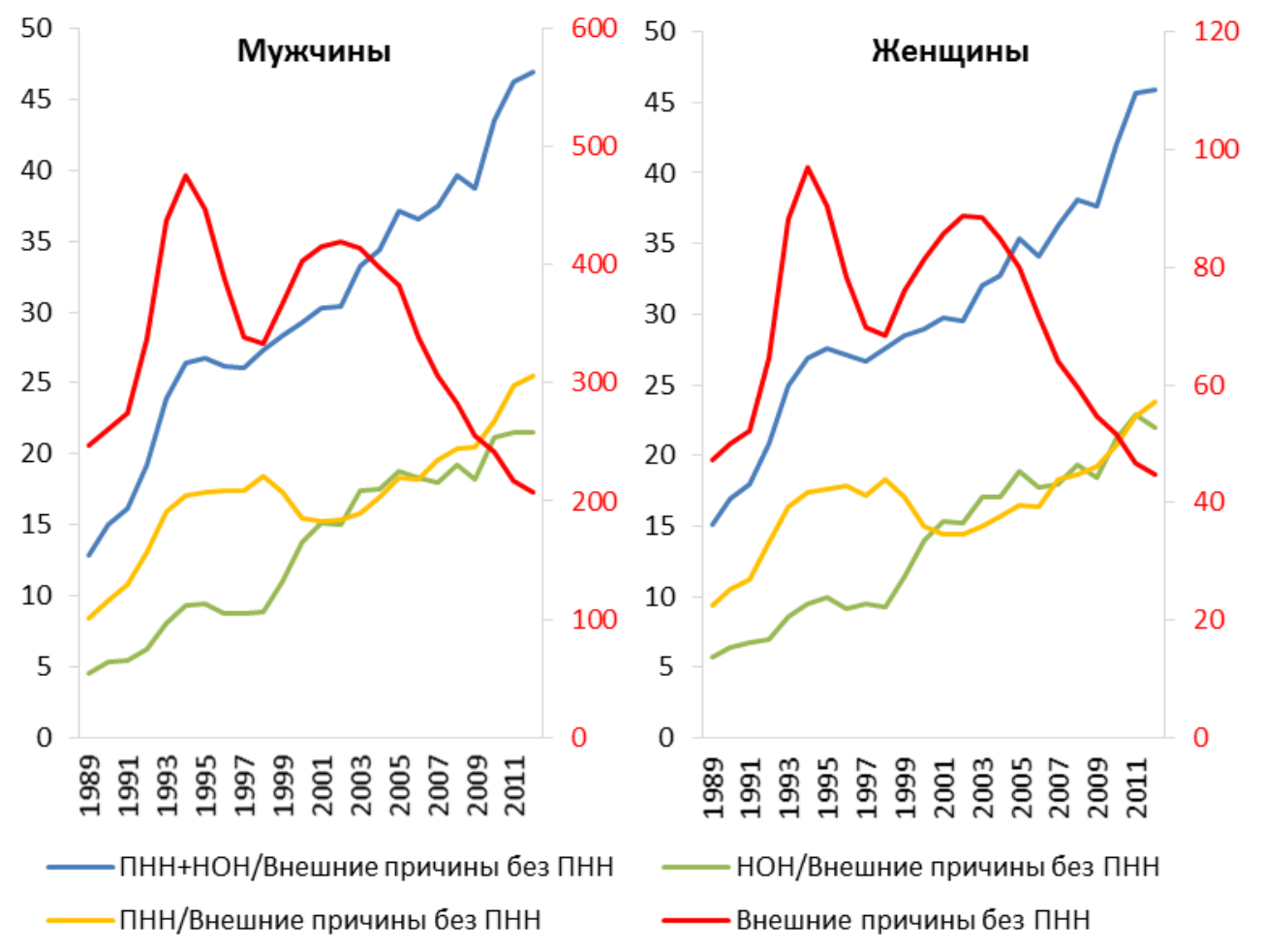

Рисунок 8. Стандартизованный коэффициент смертности от внешних причин без ПНН (на 100 000, правая ось) и его соотношение со стандартизованными коэффициентами смертности от ПНН и от НОН, на 100, в возрасте 15-59 лет

\section{4. НАРАСТАНИЕ КОНЦЕНТРАЦИИ НАСИЛЬСТВЕННОЙ СМЕРТНОСТИ В РУБРИКАХ ПНН И ЕГО ФАКТОРЫ: ОБСУЖДЕНИЕ}

Нарастание концентрации насильственной смертности в рубриках ПНН заслуживает отдельного обсуждения. Как было показано выше, проблема высокой смертности от ПНН в России существует более двух десятилетий, но особую остроту приобрела в постсоветский период: ее уровень превзошел уровень смертности от убийств и самоубийств, ее пропорция по отношению к остальным внешним причинам несоразмерно велика на фоне других стран.

И при этом она, вероятно, недооценена. Во-первых, за счет отнесения части причин, подлежащих кодированию в рубриках Ү10-Ү34, к неточно обозначенным причинам смерти (R96-R99). Во-вторых, за счет рубрик из блока отдаленных последствий повреждений, которые в ряде стран дополняют коды Y10-Y34. В США в системе NVDRS (National Violent Death Reporting System) сюда включают коды Y89.9 «Последствия неуточненных внешних причин» и Y87.2 «Последствия событий [повреждений], не уточненных как случайные или преднамеренные». В Швеции и в проекте ВО3 «Глобальные оценки здоровья» [WHO 2014: 4] добавляют только рубрику Ү87.2. В России эти причины отдельно не разрабатываются. До 2011 г. они входили в группу «Все другие случайные и неуточненные несчастные случаи, отдаленные последствия внешних причин смертности» наряду с последствиями самоповреждений (Y87.0) и нападений (Y87.1), а с 2011 г. вместе с кодами X58-X59 «Случайное воздействие других и неуточненных факторов» образуют группу «Воздействие 
факторов, не указанных в других рубриках». По имеющимся у нас данным, в 2000-2002 гг. доля смертей с кодами Y87.2 и Y89.9 составляла всего 1,4\% по отношению к блоку Ү10Y34, но с 2003 г. она начала расти и в 2010-2012 гг. достигла 5\%, что не так мало, особенно для оценки удельного веса ПНН в смертности от остальных внешних причин.

Высокий уровень насильственной смертности неустановленного рода и его тенденции нуждаются в объяснении. Один из главных вопросов заключается в том, насколько статистика смертности от ПНН отражает объективное положение вещей? Исследований, в которых не выражалось бы сомнений в этом, практически нет, и преобладает мнение, согласно которому ложная смертность от ПНН формируется главным образом за счет убийств.

В одной из первых работ, исходя из синхронного скачкообразного роста насильственной смертности неустановленного рода и смертности от убийств в 1987-1993 гг., была высказана гипотеза, что часть убийств регистрируется под этой рубрикой [Милле и др. 1996: §4.5], позже она была повторена по отношению к более длительному тренду [Chervyakov et al. 2002]. В том же духе Д.Д. Богоявленский проинтерпретировал сильную корреляцию временного и пространственного распределения показателей смертности от убийств и ПНН [Богоявленский 2000: 88, 2006: 352]. Так же, со ссылкой на региональную дифференциацию смертности, высказывались и другие исследователи: «Начиная с 1985 года, темпы роста смертности от повреждений без уточнений опережают темпы роста смертности от убийств, а на российских территориях с минимальными уровнями смертности от убийств, зачастую фиксируются максимальные уровни смертности от повреждений (без уточнений)» [Семенова и др. 2004: 13].

Предположение, что рост концентрации насильственной смертности в блоке ПНН начала 1990-х годов хотя бы отчасти был истинен, высказанное Д. Вассерманом и А. Варником, основывается на собственном опыте работы судебно-медицинским экспертом А. Варника, который возглавлял психиатрическую службу судебно-медицинской экспертизы в Эстонии, и 12 интервью со специалистами в области диагностики и кодирования насильственных смертей. Согласно [Wasserman, Värnik 1998], в советское время смертность от ПНН была поставлена под контроль, и неспособность патологоанатома отнести истинную смерть от ПНН к другим причинам критиковалась, а в случаях, когда нужно было скрыть «лишние» убийства, их кодировали как суициды [Андреев, Жданов, Школьников 2007]. Но уже в ходе горбачевской перестройки выросла степень свободы принятия решений в профессиональной сфере, а после распада СССР контроль и давление на экспертов ослабли, и «искусство» кодирования ПНН стало невостребованным. Похожей точки зрения придерживаются Е.М. Андреев с соавторами [2007], которые рассматривают ослабление в начале 1990-х годов давления на врачей со стороны статистических органов, стремящихся минимизировать неопределенные диагнозы, как один из факторов роста смертности от повреждений без уточнения их случайного или преднамеренного характера.

Заметим, что, исходя из факта усиленного контроля за смертностью от ПНН в советский период, следует признать ее уровень в то время истинным или даже заниженным, но не завышенным. Поэтому не должны вызвать сомнения ни ее рост (вместе с убийствами), ни высокие на фоне других стран значения, достигнутые к середине 1980-х годов. 
Гипотеза об ослаблении контроля за учетом внешних причин смерти не противоречит предположению, что взлет насильственной смертности неуточненного рода в постсоветский период связан с ростом смертности от убийств. Одним из факторов этого процесса стал взрыв преступности и резкий рост числа умерших от внешних причин, увеличивший нагрузку на милицию, следственные органы, патологоанатомов и судебномедицинских экспертов, с одной стороны; их низкая оплата, как и общая скудность материальных и человеческих ресурсов - с другой [Chervyakov et al. 2002; Pridemore 2003; Wasserman, Värnik 1998]. Соответственно при нехватке ресурсов для проведения расследования или экспертизы внешние причины смерти определенного рода кодировались как ПНН [Wasserman, Värnik 1998]. Логично в этом контексте выглядит гипотеза о намеренном искажении статистики смертности, особенно убийств, под давлением местной милиции или властей [Wasserman, Värnik 1998; Pridemore 2003; Värnik et al. 2010]. Но и вынужденные, и намеренные манипуляции возможны при сочетании слабого контроля за действиями врачей и процессуальных лиц с прорехами в организации регистрации насильственных смертей и в еe нормативно-правовой базе. Несовершенство законодательства способствовало росту числа неустановленных повреждений [Андреев, Жданов, Школьников 2007: 118]. Более того, при сложившейся в 1990-е годы системе регистрации насильственной смерти сведения об уровне убийств и самоубийств в статистических управлениях были выше, чем по данным правоохранительных органов, и ниже, чем по судебно-медицинскими данным [Породенко 1999]. Иначе говоря, даже если намеренно или вынужденно судебно-медицинские эксперты злоупотребляли кодами блока ПНН, часть случаев, по которым род смерти был установлен, не попадали в разработку статистических органов.

Таким образом, в отличие от предыдущего периода опережающий рост смертности неустановленного рода в 1990-х годах был отчасти сфальсифицирован, т.е. включал в себя ложные смерти от ПНН - большей частью, по общему мнению, убийства.

Поскольку все упомянутые исследования оперировали агрегированными данными, степень фальсификации неясна, а значит неясно, нарастала бы концентрация насильственной смертности в блоке ПНН без «специальных ухищрений». Теоретически, опираясь на идею, согласно которой маргинализация населения сопутствует росту смертности неустановленного рода [Милле и др. 1996: §4.5], вполне допустимо, что концентрация смертности в блоке ПНН могла нарастать «сама по себе». Косвенно 9 эта идея подтверждается тем, что в годы роста продолжительности жизни темпы ее роста были выше в тех регионах, где она была ниже, а в годы снижения - наоборот [Андреев, Вишневский 2000: 93-94; Андреев, Кваша, Харькова 2013: 398-399].

Опубликованных высказываний, объясняющих динамику смертности от ПНН или ее пропорции после 1994 г., нет или, по крайней мере, нам они не встречались. Однако, исходя из гипотез о «естественном» происхождении ускоренного роста смертности от ПНН в 19871994 гг., можно было бы ожидать, что в годы снижения смертности от внешних причин пропорция ПНН расти не будет. Действительно, в 1995-1998 гг. так и было. Но

\footnotetext{
${ }^{9}$ Если полагать, что между маргинализацией и продолжительностью жизни существует прямая зависимость и соответственно в регионах с низким уровнем дожития маргинализация выше.
} 
существенное падение числа смертей от остальных внешних причин с 2003 г., которое должно было привести как к снижению удельного веса «маргинальных» смертей, так и к уменьшению общей нагрузки на патологоанатомов, судебно-медицинских экспертов и других процессуальных лиц, вопреки ожиданиям, сопровождается ростом пропорции ПНН.

Отсутствие объяснений динамики смертности от ПНН после 1994 г., наверное, не случайно. Этому могло способствовать то, что в этот период доминирующей стала тенденции к снижению смертности от внешних причин. К тому же фокус исследований сместился на изучение природы рубрик блока Y10-Y34 на основе анализа медицинских свидетельств о смерти. В работах последнего десятилетия были рассмотрены практически все основные аспекты практики кодирования внешних причин, связанные с ПНН. Пожалуй, их главным итогом явилась проверка гипотез о принадлежности части рубрик ПНН к другим блокам внешних причин. Также был проведен анализ региональной дифференциации внешних причин и неточно обозначенных состояний, который выявил крайнее разнообразие в практике кодирования и их хаотичное изменение (неустойчивость) во времени. Кроме того, были идентифицированы прорехи в нормативно-правовой базе, содействующие излишней концентрации насильственной смертности неустановленного рода.

Результатом этих работ стала оценка скрытых в рубриках Ү10-Ү34 латентных убийств, самоповреждений и несчастных случаев, которая подтвердила сделанные ранее предположения о преобладании в смертности от ПНН латентных убийств. Однако вопрос о факторах динамки смертности от ПНН в последние годы не ставился. Между тем объяснение зеркального роста пропорции ПНН с 2003 г. вызывает особый интерес, в частности потому, что идет в разрез с гипотезами, позволяющими объяснить тенденцию роста этого показателя в предыдущие годы «естественными» факторами, не прибегая к концепции «манипуляции» с данными. Так, согласно «ресурсной гипотезе» падение числа насильственных смертей в 2003-2012 гг. должно было привести к уменьшению нагрузки на судебно-медицинских экспертов и других процессуальных лиц, а значит, - к повышению качества статистики смертности от внешних причин. Впрочем, из тех же исследований вытекает, что в качестве одного из основных факторов следует рассматривать организационные проблемы в сборе и разработке данных о внешних причинах смерти.

Организация статистики смертности по причинам смерти и ее изменения могут играть заметную роль в формировании уровня и динамики смертности от «неизвестных» причин, в том числе ПНН. В качестве примеров можно сослаться на рассмотренное выше быстрое снижение смертности от «неточно обозначенных состояний» в 1960-е годы и на резкий сдвиг соотношения смертности от этой группы причин и от ПНН в 1999-2001 гг. Кроме того, известно, что одно из принятых на коллегии Министерства здравоохранения СССР весной 1989 г. решений по совершенствованию оказания медицинской помощи при сердечно-сосудистых заболеваниях привело к росту смертности от неизвестных причин в 1989-1990 гг. [Милле и др. 1996: гл.3] и в последующие годы [Антонова 2007; Gavrilova et al. 2008].

В постсоветский период организационные изменения начались с децентрализации кодирования (шифровки) причин смерти. С советских времен кодирование производилось 
в региональных статистических управлениях. Согласно приказу Министерства здравоохранения РФ №398 [МЗ РФ 1996] с 1 января 1997 г. оно должно было осуществляться врачами лечебно-профилактических учреждений и больниц.

Передача этой функции из одного ведомства в другое и с регионального на низовой уровень породила «значительные трудности из-за отсутствия соответствующих методических материалов» [КЗ СПб 1997]. Вместе с функцией шифровки причин смерти органы статистики утратили и функцию проверки полноты, правильности заполнения и кодирования медицинских свидетельств о смерти по основной причине смерти.

Потенциально проведенная реорганизация могла привести к нарушению сопоставимости во времени статистики по причинам смерти и к ухудшению ее качества. Правда, эффект от нововведений в меньшей степени должен был сказаться на учете смертей от внешних причин, в установлении которых участвуют процессуальные лица. Но поскольку в то время законодательство возлагало на врача определение или, по крайней мере, запись во врачебное свидетельство внешней причины при смерти от травм и отравлений [Богоявленский 2000: 88; Андреев, Жданов, Школьников 2007: 118], данная реорганизация могла иметь последствия для учета смертности от внешних причин, включая смертность от ПНН. В частности, она могла сказаться при переходе с 1999 г. на 10-й пересмотр МКБ и породить пресловутый перевод части ПНН в рубрики неточно обозначенных состояний в 1999-2001 гг.

Даже сам по себе переход на МКБ-10, как свидетельствует международный опыт, мог повлиять на динамику доли смертности от ПНН. Исследование, проведенное в Италии, показало, что переход на МКБ-10 сильно воздействовал на 8 из 15 категорий внешних причин, правда, между крупными блоками (несчастных случаев, убийств и самоубийств) взаимообмена не было [Gjertsen et al. 2013]. С другой стороны, резкие перепады в уровне показателя часто совпадают с годом перехода к новому пересмотру МКБ. Например, в Японии доля ПНН в смертности от остальных внешних причин увеличивалась много лет, но в 1995 г. сократилась почти троекратно, а с 1996 г. возобновила рост, так что по сравнению с 1995 г. в 2010 г. ее значения выросли в 2 раза у мужчин и в 2,5 раза у женщин. Из 14 стран (без Румынии, для которой временной ряд начинается сразу с МКБ-10) в девяти наблюдалось падение показателя, наиболее очевидное в Португалии, Японии, Франции, Италии.

В России введение в 1999 г. МКБ-10 не вызвало резких колебаний в уровне смертности от ПНН, но именно с этого года он неожиданно начал снижаться на фоне увеличения смертности от остальных внешних причин, что, как говорилось выше, может объясняться отнесением части смертей от ПНН к неизвестным причинам смерти. На это совпадение обратила внимание О.И. Антонова [2007: 105], а в отношении детских возрастов - И. Шурыгина [2013], и хотя этот вопрос остается открытым, представляется, что совпадение неслучайно и что помимо перехода на МКБ-10 к нему привело и то, как именно происходил этот переход.

В 1998 г. при переходе на МКБ-10 вместе с введением новой формы медицинского свидетельства о смерти [МЗ РФ 1998] были отменены действовавшие с 1984 г. инструкции по его выдаче и заполнению, а новые не были утверждены. Инструкции, а точнее, 
рекомендации, появились спустя десять лет - в январе 2009 г. [МЗСР 2009]. Они регулируют порядок выдачи предварительных и окончательных медицинских свидетельств о смерти, а также попадание в статистическую разработку окончательного вердикта. По мнению С.Ю. Никитиной и Г.М. Козеевой [2006], из-за их отсутствия упало качество заполнения медицинских свидетельств и кодирования причин смерти, увеличились сроки заполнения окончательных медицинских свидетельств, и, главное, окончательные медицинские свидетельства не только перестали поступать в органы государственной статистики, но и вообще перестали выписываться, что сильно отразилось на статистке внешних причин смерти. Так, данные разработки Мосгорстата и данные бюро судебномедицинской экспертизы г. Москвы о числе умерших от отравлений алкоголем в 2000-2005 гг. расходятся в 4-6 раз, причем с 2001 по 2005 г. величина расхождения постоянно увеличивалась [Никитина, Козеева 2006: таблица 2].

Однако возвращение инструктивных документов, а также публикация руководства по кодированию причин смерти в 2008 г. в соответствии с МКБ-10 не повлияли на динамику как смертности от ПНН и от остальных внешних причин, так и на их соотношение. Кроме того, анализируя медицинские свидетельства о смерти за 2010 г. в возрастах 15-59 лет по России в целом, А.Е. Иванова и соавторы [2013] обнаружили схожую проблему: установленная в ходе расследования истинная причина смерти не попадает в статистическую разработку. Дополнительное исследование за 2011 г. показало, что дело не столько в том, что не выписывается окончательное (взамен предварительного) медицинское свидетельство, а в том, что не выписывается предварительное свидетельство. Источник этого небрежения авторы исследования видят в сложившейся в стране нормативноправовой базе, а именно, в приказе МЗ РФ №61 от 24.04.03 «Об утверждении инструкции по организации и производству экспертных исследований в бюро судебно-медицинской экспертизы», пункт 2.2.7.2 которого допускает двоякое толкование:

- с одной стороны, если для установления или уточнения причины смерти необходимо проведение лабораторных исследований, то выдают предварительное свидетельство, а сразу после их проведения - окончательное взамен предварительного;

- с другой, стороны, невозможность установления рода смерти или обстоятельств и места травмы к моменту выдачи свидетельства о смерти не является основанием для выдачи предварительного свидетельства о смерти; в этом случае в бланке подчеркивают "род смерти не установлен".

Это второе возможное толкование - главный фактор, из-за которого установленный в ходе расследования род смерти не попадает в статистическую разработку, что в свою очередь объясняет высокий удельный вес блока Y10-Y34 в смертности от внешних причин. Нужно подчеркнуть, что двусмысленность трактовки дополняется двусмысленностью сложившейся ситуации после отмены в 2010 г. приказа №161[МЗСР 2010b]. Он вроде бы утратил свою силу, но вышедшей чуть ранее приказ [МЗСР 2010а] вместо инструкции утвердил порядок организации и производства судебно-медицинской экспертизы, и возможно поэтому никак не регулирует выдачу того или иного типа свидетельства о смерти. 
Тем самым практика выдачи не предварительного, а сразу окончательного свидетельства о смерти с открытым вердиктом сохраняется до сих пор ${ }^{10}$.

Появление этой инструкции совпало с началом нынешней фазы «зеркального роста» пропорции ПНН, поэтому возможно, что именно появление инструкции способствовало стартовавшему с 2003 г. снижению смертности от внешних причин и продлению роста смертности от ПНН до 2005 г., а сама инструкция - один из факторов, на котором держится данная взаимосвязь.

Выдача сразу окончательного медицинского свидетельства о смерти в случаях, когда должно быть выдано предварительное, и непопадание в статистическую разработку окончательного (взамен предварительного) свидетельства - фундаментальный изъян организации учета смертности от внешних причин. О другом изъяне - использовании показателей смертности от конкретных рубрик внешних причин в качестве критериев оценки работы тех или иных учреждений или управления территориями - известно мало. Обычно он подразумевается в рассуждениях о социальной значимости статистики смертности от убийств, самоубийств, отравлений алкоголем и наркотиками, его роль более очевидна при контроле за выполнением программ, нацеленных на борьбу со смертностью от конкретных классов и причин смерти, в том числе внешних, например, ДТП, алкогольных отравлений. Таких программ разработано немало после утверждения Концепции демографической политики Российской Федерации в 2007 г., и бывает, что это приводит «к вызывающим сомнение очень сильным снижениям коэффициентов смертности» [Кваша, Харькова 2011].

Само по себе принятие показателя смертности от той или иной причины в качестве критерия естественно, но при отсутствии контроля создает мотив для манипуляции с данными - давно утвердившаяся среди отечественных исследований гипотеза, которая, в частности, объясняет чрезмерно высокий процент смертей неустановленного рода. Один из ярких примеров подобных манипуляций приводят Иванова с соавторами [2013]: смертность от случайных отравлений алкоголем (X45) является в России социально значимым показателем, который отслеживается и региональным, и федеральным руководством, и перевод этих потерь в латентную форму (в частности, в ПНН, Ү15) позволяет заметно улучшить показатели смертности от алкогольных отравлений, не прикладывая никаких усилий для реального улучшения ситуации.

В целом из приведенного анализа организации и нормативного регулирования сбора и разработки статистики внешних причин смерти можно сделать вывод, что эти факторы создают основу для умышленного и неумышленного искажения статистки смертности от внешних причин, что, в свою очередь, может поддерживать тенденцию к нарастанию и без того высокой степени неопределенности в истинном уровне смертности от убийств и самоповреждений в последние годы. Но только ли они? Не может ли быть так, что зеркальный рост пропорции ПНН в 2003-2012 гг. носит естественный характер?

10 Так считают авторы цитируемого исследования, исходя из анализа ситуации в 2011 г. [Иванова и др. 2013]. 
В какой-то мере прояснить это можно, переформулировав вопрос: свойственны ли аналогичное периоды странам, где нет таких, как в России, проблем со статистикой внешних причин?

Выше уже говорилось, что среди отобранных для сравнения стран нарастание концентрации смертей от внешних причин в блоке ПНН в течение двух десятилетий - не редкость. При этом в большинстве из них преобладающей является тенденция снижения смертности от внешних причин. Поэтому периоды зеркального роста пропорции ПНН отмечаются в целом ряде стран: Австрии, Болгарии, Венгрии, Великобритании, Польше, США, Швеции, Японии. Учитывая достаточно широкую распространенность этого явления в странах, где проблема злоупотребления рубриками блока ПНН не стоит так остро, как в России, можно допустить, что рост пропорции этих причин носит естественный характер. Но чем объясняется такой тренд? Если отталкиваться от факта концентрации риска смертности от внешних причин (в первую очередь от самоубийств, убийств и ПНН) в социально уязвимых слоях населения, что согласуется с исследованиями по социальной дифференциации смертности, то рост удельного веса причин неустановленного рода в этих странах может означать, что снижение смертности от внешних причин в меньшей степени затрагивает именно эти слои.

В России неравенство в доходах выражено сильнее, смертность от ПНН концентрируется в маргинальных слоях населения [Иванова и др. 2004], проблема маргинализации масштабнее и отягощена алкогольным синдромом. Следовательно, если выдвинутая гипотеза верна, рост пропорции ПНН при сокращении смертности от остальных внешних причин в России может иметь те же корни, а сама пропорция должна быть выше, чем в сравниваемых странах. Правда, прямая аналогия с ситуацией в восьми упомянутых странах может быть не вполне оправдана: в России в структуре блока Y10-Y34 важную роль играют рубрики, связанные с убийствами, а не с самоубийствами и несчастными случаями, как в этих странах. Поэтому, хотя опыт многих развитых стран свидетельствует, что зеркальный рост пропорции ПНН не является плодом манипуляций со статистикой, вопрос о его природе в России требует дальнейшего изучения.

\section{5. ЗАКЛЮЧЕНИЕ}

Анализ долговременных трендов смертности от ПНН в России показывает, что особенностью периодов повышения смертности от внешних причин в России был опережающий рост смертности от ПНН, который привел к необычайно высокому уровню смертности от этого блока причин и соответственно к нарастанию «неопределенности» в отношении истинного уровня смертности от намеренных и случайных повреждений. Продолжающееся с 2003 г. снижение смертности от внешних причин не только не переломило эту тенденцию, но и усилило ее: в 2010 г. стандартизованный коэффициент смертности от ПНН превысил уровень смертности от самоубийств. Теперь проблема заключается не в том, что смертность от ПНН продолжает теснить смертность от остальных внешних причин, так как похожие тренды наблюдались и в других странах, а в том, что это происходит, когда пропорции смертности неустановленного рода уже достигли необычайно высоких значений. 
Доля смертей неизвестного рода увеличилась не только за счет повреждений с неопределенными намерениями, свой вклад внесли и причины, входящих в 13-й блок 18-го класса (R00-R99) «Другие неточно обозначенные и неуточненные причины смерти», в которые, судя по многочисленным косвенным свидетельствам, в ряде регионов перебрасываются смерти, принадлежащие внешним причинам, преимущественно ПНН [Иванова и др. 2013]. Складывается своеобразная система регуляции статистики смертности от внешних причин: случаи смерти от социально значимых внешних причин фиксируются как смерти от повреждений с неопределенными намерениями, часть которых (можно сказать, истинные смерти неизвестного рода) перенаправляется за пределы класса внешних причин. Это явление, названное «переводом социально значимых причин в латентную (Y10-Y34, R96-R99) форму» [Иванова и др. 2013], имеет важные последствия для осуществления программ, нацеленных на борьбу с высокой смертностью от внешних причин в России, и должно учитываться при их разработке и реализации.

Вместе с тем похожие проблемы в статистике внешних причин смерти встречаются и в других странах. Иногда они носят объективный характер (трудности определения намерения при утоплениях, отравлениях, падениях), иногда отражают национальные особенности кодирования. В частности, можно указать на несоразмерно высокий уровень смертности от неточно обозначенных состояний в ряде европейских стран [Rockett, Kapusta, Bhandari 2011] и высокую пропорцию смертей от ПНН во внешних причинах в некоторых странах Европейского союза. Отдельной проблемой является идентификация насильственных причин смерти младенцев и годовалых детей. Очень высокий (выше, чем в России) удельный вес ПНН (в Эстонии в 2001-2005 гг. он составлял 26\%) обусловлен небрежностью в проведении расследования, т.е. без выяснения необходимых деталей обстоятельств смерти, даже без осмотра места смерти [Väli et al. 2007]. Есть веские основания считать, что среди таких инцидентов значительный процент составляют латентные убийства. Например, свыше 40\% смертей ПНН среди младенцев и маленьких детей в США (Калифорния 1961-1991 гг.) были похожи на убийства [Sorenson, Shen, Kraus 1997а], что во многом проистекает из трудностей расследования смертей, вызванных ненадлежащим уходом за малолетними детьми. Так же, как в России, в США есть штаты, в которых практика кодирования внешних причин резко отличается от соседних, и, что еще больше дополняет сходство с ситуацией в России, непредсказуемо меняется во времени [Breiding, Wiersema 2006]. Там же существует организационные изъяны во взаимодействии разных ведомств, которые могут приводить к тому, что для одного и того же случая смерти ее причина фиксируется по-разному в разных ведомствах: коронер/судебно-медицинский эксперт фиксирует убийство, в полицейском отчете указывается несчастный случай, а в медицинском свидетельстве о смерти - ПНН [Parks et al. 2014]. И даже есть прецеденты давления со стороны властей, приведшего к резкому сокращению смертности от самоубийств и ее взлету от случайных отравлений, как это было в 1980-х годах в Нью-Йорке [Whitt 2006]. Наконец, судя по анализу долговременных трендов в 14 странах, не так редки резкие перепады в уровне смертности от ПНН при переходе на новый пересмотр МКБ.

Однако сходство не так принципиально, как различие. В большинстве развитых стран статистика по причинам смерти детальнее и доступнее для исследователей. Разработка множественных причин смерти, тем более в сочетании с социально- 
демографическими характеристиками, а в странах, имеющих регистр населения, и с другими данными ${ }^{11}$, существенно расширяет возможности контроля и исправления ее дефектов. Проводятся исследования, в которых сведения из медицинского свидетельства о смерти сопоставляются с данными судебно-медицинской экспертизы. Вводятся дополнительные меры по улучшению идентификации насильственных причин, например, психологической аутопсии и нарративной аутопсии (в Англии), а также, что крайне актуально для России, создаются системы мониторинга внешних причин смерти. Например, системы отчетности о смертности от насилий в США (National Violent Death Reporting System, NVDRS), в Австралии и Новой Зеландии (National Coronial Information System, NCIS) объединяют и систематизируют в единую базу данных информацию из отделов расследования убийств, криминалистических лабораторий, отчетов коронеров, судебно-медицинских экспертов и свидетельств о смерти.

В том же направлении в последние годы развивается статистика по причинам смерти в России. Но главное, что отличает Россию: масштаб и исторические корни проблемы. Последнее не менее важно. Уильям Придемор, обнаружив, что в 1990-е годы число убийств по данным МВД занижено по сравнению с данными Минздрава, выдвинул гипотезу, что МВД не справляется с высоким уровнем насилия и многих дел просто не возбуждает. По его мнению, «в это нетрудно поверить, принимая во внимание историю фальсификаций статистики преступлений в России под давлением требований снизить уровень преступности» [Pridemore 2003]. Есть основания распространить это наблюдение на статистику смертности от внешних причин.

\section{ЛИТЕРАТУРА}

Андреев Е.М., А.Г. Вишневский (2000). Смертность и продолжительность жизни // Население России 2000: восьмой ежегодный демографический доклад / Отв. ред. А. Г. Вишневский. М.: Институт народнохозяйственного прогнозирования РАН, Центр демографии и экологии человека: 82-100.

Андреев Е.М., Д.А. Жданов, В.М. Школьников (2007). Смертность в России через 15 лет после распада СССР: факты и объяснения / SPERO. №6:115-142: 118.

Андреев Е.М., Е.А. Кваша, Т.Л. Харькова (2013). Смертность и продолжительность жизни // Население России 2010-2011: восемнадцатый-девятнадцатый ежегодный демографический доклад / Отв. ред. А. Г. Вишневский. М.: Изд. дом Высшей школы экономики: 385-443.

Антонова О. И. (2007). Региональные особенности смертности населения от внешних причин // Диссертация на соискание ученой степени кандидата экономических наук: 08.00.05. М.

Архангельский В.Н., А.Е. Иванова, Л.Л. Рыбаковский, С.В. Рязанцев (2006).

Демографическая ситуация в Москве и тенденции ее развития. М.: Центр социального прогнозирования.

${ }^{11} \mathrm{C}$ судимостями, обращением за психиатрической помощью и др. (например, Швеция). 
Богоявленский Д.Д. (2000). Самоубийства в Удмуртии // Политика по контролю кризисной смертности в России в переходный период / под ред. Школьникова В.М., Червякова В.В. М.: ПРООН.

Богоявленский Д.Д. (2006). Динамика смертности от отдельных внешних причин. Структура смертности от внешних причин // Демографическая модернизация России. 1900-2000 / под ред. А.Г. Вишневского. М.: Новое издательство: 340-355.

ВОЗ (2003). Международная статистическая классификация болезней и проблем, связанных со здоровьем: МКБ-10. В 3-х томах. Том 2. М.: Медицина.

Иванова А.Е., Т.П. Сабгайда, В.Г. Семенова, В.Г. Запороженко, Е.В. Землянова, С.Ю. Никитина (2013). Факторы искажения структуры причин смерти трудоспособного населения России // «Социальные аспекты здоровья населения». 4(32). URL: http://vestnik.mednet.ru/content/view/491/30/lang,ru/ (дата обращения: 20.03.2014).

Иванова А., В. Семенова, Е. Дубровина (2004). Маргинализация российской смертности // Демоскоп Weekly. №181-182. URL: http://demoscope.ru/weekly/2004/0181/tema01.php (дата обращения: 13.11.2014).

Кваша Е.А., Т.Л. Харькова (2011). Программы, направленные на снижение смертности приняты. Каковы их результаты? // Демоскоп-Weekly. № 463 - 464, URL: http://demoscope.ru/weekly/2011/0463/analit04.php\#_FN_4 (дата обращения: 2.05.2014).

КЗ СПб (1997). Приказ Комитета по здравоохранению Администрации Санкт-Петербурга от 18 марта 1997 г. №98 «О введении в действие инструктивно-методических материалов по кодированию причин смерти в медицинской документации».

Милле Ф., В. Школьников, В. Эртриш, Ж. Валлен (1996). Современные тенденции смертности по причинам смерти в России 1965-1994 // Donnesdestatistiques. №2. Paris: INED. http://demoscope.ru/weekly/knigi/shkol/shkol.html (дата обращения 26.09.2013).

МЗ РФ (1996). Приказ Министерства здравоохранения Российской федерации от 04 декабря 1996 г. №398 «О кодировании (шифровке) причин смерти в медицинской документации».

МЗ РФ (1998). Приказ Министерства здравоохранения Российской Федерации от 07 августа 1998 г. №241 "О совершенствовании медицинской документации, удостоверяющей случаи рождения и смерти, в связи с переходом на МКБ-Х».

МЗСР (2009). Письмо Министерства здравоохранения и социального развития РФ от 19 января 2009 г. №14-6/10/2-178 «О порядке выдачи и заполнения медицинских свидетельств о рождении и смерти».

МЗСР (2010а). Приказ Министерства здравоохранения и социального развития РФ от 12 мая 2010 г. №346н "Об утверждении Порядка организации и производства судебномедицинских экспертиз в государственных судебно-экспертных исследований в бюро судебно-медицинской экспертизы».

МЗСР (2010b). Приказ Министерства здравоохранения и социального развития РФ от 04 июня 2010 г. №423н "О признании утратившим силу Приказа Министерства здравоохранения Российской Федерации от 24 апреля 2003 г. №161 "Об утверждении Инструкции по организации и производству экспертных исследований в бюро судебно-медицинской экспертизы".

Никитина С.Ю., Г.М. Козеева (2006). Совершенствование статистики смертности от алкоголизма // Вопросы статистики. №11: 21-23. 
Породенко В.А., В.В. Чернобай (1999). Современные тенденции в динамике насильственной и ненасильственной смерти и проблемы их учета // Судебномедицинская экспертиза. № 5: 20-23.

Руководство по кодированию причин смерти (2008). М.: ЦНИИОИЗ. URL: www.mednet.ru/images/stories/files/statistika/organizacionnometodicheskie_materialy/Rukovodstvo_po_kodirovaniyu_prichin_smerti.pdf (дата обращения 26.09.2013).

Семенова В.Г., О.И. Антонова (2007). Достоверность статистики смертности (на примере смертности от травм и отравлений в Москве) // Социальные аспекты здоровья населения. №2 http://vestnik.mednet.ru/content/view/28/30/ (дата обращения 26.09.2013).

Семенова В.Г., Н.С. Гаврилова, Г.Н. Евдокушкина, Л.А. Гаврилов (2004). Качество медико-статистических данных как проблема современного российского здравоохранения // Общественное здоровье и профилактика заболеваний. (2): 11-19.

Шурыгина И.И. (2013). Смертность российских детей от внешних причин // Демоскоп Weekly. №537-538. URL: http://www.demoscope.ru/weekly/2013/0537/demoscope537.pdf (дата обращения: 17.10.2014).

Andreev E. M. (2010). A VBA program for data extraction from the WHO Mortality Database // MPIDR Technical Report TR-2010-004. Rostock. URL:

http://www.demogr.mpg.de/en/projects_publications/publications_1904/mpidr_technical_rep orts/a_vba_program_for_data_extraction_from_the_who_mortality_database_3840.htm (data accessed: 30.01.2014).

Begg S., N. Tomijima (2003). Global burden of injury in the year 2000: an overview of methods. Geneva: World Health Organization.

Bjorkenstam C., L.-A. Johansson, P. Nordstrom, I. Thiblin, A.Fugelstad, J.Hallqvist, R.Ljung (2014). Suicide or undetermined intent? A register-based study of signs of misclassification // Population Health Metrics. 12: 1-11.

Breiding M.J., B. Wiersema (2006). Variability of undetermined manner of death classification in the US // Injury Prevention. 12 (SUPPL. 2): ii49-ii54.

Castro E.F. de, F. Pimenta, I. Martins (1989). The truth about suicide in Portugal // Acta Psychiatrica Scandinavica. 80(4): 334-339.

Chang S.-S., J.A.C. Sterne, T.-H. Lu, D. Gunnell (2010). Hidden' suicides amongst deaths certified as undetermined intent, accident by pesticide poisoning and accident by suffocation in Taiwan // Social Psychiatry and Psychiatric Epidemiology. 45(2): 143-152.

Chervyakov V.V., V.M. Shkolnikov, W.A. Pridemore, M. McKee (2002). The changing nature of murder in Russia // Social Science \& Medicine. 55(10): 1713-1724.

Danilova I., F. Mesle, J. Vallin (2014). Reconstruction of coherent cause-specific mortality time series for Russia and its regions // European Population Conference Budapest. Hungary, 2528 June. Budapest.

Drumond M.Jr., M.M. Lira, M.D. Freitas, T.M. Nitrini, K. Shibao (1999). Evaluation of the quality of mortality information by unspecified accidents and events of undetermined intent // Revista De Saúde Pública. 33(3): 273-280.

Gavrilova N.S., V.G. Semyonova, E. Dubrovina,, G.N. Evdokushkina, A.E. Ivanova, L.A. Gavrilov (2008). Russian Mortality Crisis and the Quality of Vital Statistics // Population Research and Policy Review. 27(5): 551-574. 
Gjertsen F., L.A. Johansson (2011). Changes in statistical methods affected the validity of official suicide rates // Journal of Clinical Epidemiology. 64(10): 1102-1108.

Gjertsen F., S. Bruzzone, M.E. Vollrath, M. Pace, Ø. Ekeberg (2013). Comparing ICD-9 and ICD-10: the impact on intentional and unintentional injury mortality statistics in Italy and Norway // Injury. 44(1): 132-138.

Hofer P., I.R.H. Rockett, P. Värnik, E. Etzersdorfer, N.D. Kapusta (2012). Forty years of increasing suicide mortality in Poland: Undercounting amidst a hanging epidemic? // BMC Public Health. 12(644):1-9.

Horte L.G. (1983). Ovisshetett problem isuicid statistiken (Uncertainty - a problem in the statistics on suicide) // I. Hygiena. 92: 25. - цит. по [Wasserman, Varnik 1998].

Kapusta N.D., U.S. Tran, I.R. Rockett, D. De Leo, C.P. Naylor, T. Niederkrotenthaler, M. Voracek, E. Etzersdorfer, G. Sonneck (2011). Declining autopsy rates and suicide misclassification: A cross-national analysis of 35 countries // Archives of General Psychiatry. 68(10): 1050-1057.

Kolmos L. (1987). Suicide in Scandinavia. Anepidemiologicalanalysis // Acta Psychiatrica Scandinavica. 76(Suppl336): 11-16

Meslé F., J. Vallin, V. Hertrich, E. Andreev, V. Shkolnikov (2003). Causes of death in Russia: assessing trends since the 1950s // European Population Conference «Population of Central and Eastern Europe. Challenges and Opportunities» / Irena E. Kotowska and Janina Józwiak, eds. Statistical Publishing Establishment. Warsaw: 389-414. URL: http://demoscope.ru/weekly/knigi/epc.php (датаобращения11.07.2014).

O’Carroll P.W. (1989). A consideration of the validity and reliability of suicide mortality data // Suicide Life Threat Behavior. 19(1): 1-16.

Parks S.E., L.L. Johnson, D.D McDaniel., M. Gladden (2014). Surveillance for violent deathsnational violent death reporting system, 16 states, 2010 // MMWR Surveillance Summaries. 63: $1-33$.

Pridemore W.A. (2003). Measuring homicide in Russia: a comparison of estimates from the crime and vital statistics reporting systems // Social Science \& Medicine. 57(8): 1343-1354.

Rockett I.R., N.D. Kapusta, R. Bhandari (2011). Suicide misclassification in an international context: revisitation and update // Suicidology Online. 2: 48-61.

Ruzicka Lado T. (1996). A note on suicide I Russia, 1963-1993 // Journal of the Australian Population Association. Vol.16 (2: 187-193.

Sorenson S.B., H. Shen, J.F. Kraus (1997a). Coroner-Reviewed Infant and Toddler Deaths: Many «Undetermineds» Resemble Homicides // Evaluation Review. 21(1): 58-76.

Sorenson S.B., H. Shen, J.F. Kraus (1997b). Undetermined Manner of Death: A Comparison With Unintentional Injury, Suicide, and Homicide Death // Evaluation Review. 21(1): 43-57.

Tøllefsen I.M., E. Hem, Ø. Ekeberg (2012). The reliability of suicide statistics: a systematic review // BMC Psychiatry. 12(9): 1-11.

Väli M., K. Lang, R. Soonets, M. Talumäe, A.M. Grjibovski (2007). Childhood deaths from external causes in Estonia, 2001-2005 // BMC Public Health. 7(1): 158.

Värnik P., M. Sisask, A. Värnik, A. Yur'Yev, K. Kolves, L. Leppik, A. Nemtsov, D. Wasserman (2010). Massive increase in injury deaths of undetermined intent in ex-USSR Baltic and Slavic countries: Hidden suicides? // Scandinavian Journal of Public Health. 38(4): 395-403. 
Värnik P., M. Sisask, A. Värnik, E. Arensman, C.V. Audenhove, C.M. van der Feltz-Cornelis, U.Hegerl (2012). Validity of suicide statistics in Europe in relation to undetermined deaths: developing the 2-20 benchmark // Injury Prevention. 18(5): 321-325.

Wasserman D., A. Värnik (1998). Reliability of statistics on violent death and suicide in the former USSR, 1970-1990 // Acta Psychiatrica Scandinavica. 98(S394): 34-41.

Whitt H.P. (2006). Where Did the Bodies Go? The Social Construction of Suicide Data, New York City, 1976-1992 // Sociological Inquiry. 76(2): 167-186.

WHO mortality database. URL: http://www.who.int/healthinfo/mortality_data/en/ (data accessed: 30.01.2014).

WHO (2014). WHO methods and data sources for country level causes of death 20002012 / Global Health Estimates Technical Paper WHO/HIS/HSI/GHE/2014.7 


\section{MORTALITY FROM UNDETERMINED CAUSES OF DEATH IN RUSSIA AND IN A SELECTED SET OF COUNTRIES}

\section{SERGEY VASIN}

Sergey A. Vasin. Institute of Demography, National Research University Higher School of Economics. E-MAIL: svasin@hse.ru. DATE RECEIVED: September 2015.

Deaths due to injuries and poisoning which experts could not identify as homicide, suicide or accident are registered in statistics as deaths due to an event of undetermined intent. The proportion of such deaths can indicate the quality of the statistics of causes of death, above all of the statistics of intentional self-harms and assaults. In Russia, the proportion of deaths due to events of undetermined intent among other external causes has been growing for almost four decades. Such a trend was observed in the past during periods of growing mortality of external causes. Yet the steady and long decline in mortality from external causes in Russia that began in 2003 has not stopped the trend. The pushing aside of other external causes continues, though mortality from events of undetermined intent has exceeded both suicide and homicide mortality, and its proportion has increased tenfold, reaching very high levels relative to other countries. In a number of studies done in Russia over the past decade it was argued that such a high proportion depends largely on manipulations with statistics of mortality from external causes, the so-called conversion of socially important causes of death to a latent form.

Based on a review of relevant research and long-term trends of mortality from external causes in Russia and in a selected set of developed countries, the factors behind the persistent rise of the proportion of deaths due to events of undetermined intent are analysed. This makes it possible to expand the contextual framework of the discussion about the factors of the persistent growth of this 'technical' indicator and about the hypothesis of the 'natural' character of such dynamics.

Key words: mortality, Russia, external causes of death, homicide, suicide, event of undetermined intent, illdefined and unknown causes of death, quality of external causes of death statistics.

\section{REFERENCES}

Andreev E. M. (2010). A VBA program for data extraction from the WHO Mortality Database // MPIDR Technical Report TR-2010-004. Rostock. URL:

http://www.demogr.mpg.de/en/projects_publications/publications_1904/mpidr_technical_rep orts/a_vba_program_for_data_extraction_from_the_who_mortality_database_3840.htm (data accessed: 30.01.2014).

Andreev E.M., E.A. Kvasha, T.L. Kharkova (2013). Smertnost' i prodolzhitel'nost' zhizni [Mortality and life expectancy] // Naselenie Rossii 2010-2011: vosemnadcatyjdevyatnadcatyj ezhegodnyj demograficheskij doklad [Population of Russia 2000: the 18th annual demographic report] / Otv. red. A. G. Vishnevsky. M.: Izd. dom Vysshej shkoly ehkonomiki: 385-443.

Andreev E.M., A.G. Vishnevsky (2000). Smertnost' i prodolzhitel'nost' zhizni [Mortality and life expectancy] // Naselenie Rossii 2000: vos'moj ezhegodnyj demograficheskij doklad [Population of Russia 2000: the 18th annual demographic report] / Otv. red. A. G. Vishnevsky. M.: Institut narodnohozyajstvennogo prognozirovaniya RAN, Centr demografii i ehkologii cheloveka: 82-100.

Andreev E.M., D.A. Zhdanov, V.M. Shkolnikov (2007). Smertnost' v Rossii cherez 15 let posle raspada SSSR: fakty i ob"yasneniya [Mortality in Russia at 15 years after the USSR collapse: facts and explanations] / SPERO, №6:115-142. http://spero.socpol.ru/docs/N6_2007-115142.pdf 
Antonova O. I. (2007). Regional'nye osobennosti smertnosti naseleniya ot vneshnih prichin [Regional peculiarities of mortality from external causes of death]. Dissertaciya na soiskanie uchenoj stepeni kandidata ehkonomicheskih nauk: 08.00.05. Moskva.

Arhangel'sky V.N., A.E. Ivanova, L.L. Rybakovsky, S.V. Ryazancev (2006).

Demograficheskaya situaciya v Moskve i tendencii ee razvitiya [Demographic situation and demographic development in Moscow]. Centr social'nogo prognozirovaniya.

Begg S., N. Tomijima (2003). Global burden of injury in the year 2000: an overview of methods. Geneva: World Health Organization.

Bjorkenstam C., L.-A. Johansson, P. Nordstrom, I. Thiblin, A. Fugelstad, J. Hallqvist, R. Ljung (2014). Suicide or undetermined intent? A register-based study of signs of misclassification // Population Health Metrics. 12: 1-11.

Bogoyavlensky D.D. (2000). Samoubijstva v Udmurtii // Politika po kontrolyu krizisnoj smertnosti v Rossii v perekhodnyj period / pod red. Shkolnikova V.M., Chervyakova V.V. M.: PROON.

Bogoyavlensky D.D. (2006). Dinamika smertnosti ot otdel'nyh vneshnih prichin. Struktura smertnosti ot vneshnih prichin [Structure and trends of mortality from exterbal causes of death] // Demograficheskaya modernizaciya Rossii. 1900-2000 [Demographic modernization of Russi. 1900-2000] / pod red. A.G. Vishnevskogo. M.: Novoe izdatel'stvo: 340-355.

Breiding M.J., B. Wiersema (2006). Variability of undetermined manner of death classification in the US // Injury Prevention. 12 (SUPPL. 2): ii49-ii54.

Castro E.F. de, F. Pimenta, I. Martins (1989). The truth about suicide in Portugal // Acta Psychiatrica Scandinavica. 80(4): 334-339.

Chang S.-S., J.A.C. Sterne, T.-H. Lu, D. Gunnell (2010). Hidden' suicides amongst deaths certified as undetermined intent, accident by pesticide poisoning and accident by suffocation in Taiwan // Social Psychiatry and Psychiatric Epidemiology. 45(2): 143-152.

Chervyakov V.V., Shkolnikov V.M., Pridemore W.A., McKee M. (2002). The changing nature of murder in Russia // Social Science \& Medicine. 55(10): 1713-1724.

Danilova I., F. Mesle, J. Vallin (2014). Reconstruction of coherent cause-specific mortality time series for Russia and its regions // European Population Conference Budapest, Hungary, 2528 June. Budapest.

Drumond M. Jr., M.M. Lira, M.D. Freitas, T.M. Nitrini, K. Shibao (1999). [Evaluation of the quality of mortality information by unspecified accidents and events of undetermined intent] // Revista De Saúde Pública. 33(3): 273-280.

Gavrilova N.S., V.G. Semyonova, E. Dubrovina, G.N. Evdokushkina, A.E. Ivanova, L.A. Gavrilov (2008). Russian Mortality Crisis and the Quality of Vital Statistics // Population Research and Policy Review. 27(5): 551-574.

Gjertsen F., L.A. Johansson (2011). Changes in statistical methods affected the validity of official suicide rates // Journal of Clinical Epidemiology. 64(10): 1102-1108.

Gjertsen F., S. Bruzzone, M.E. Vollrath, M. Pace, Ø. Ekeberg (2013). Comparing ICD-9 and ICD-10: the impact on intentional and unintentional injury mortality statistics in Italy and Norway // Injury. 44(1): 132-138.

Hofer P., I.R.H. Rockett, P. Varnik, E. Etzersdorfer, N.D. Kapusta (2012). Forty years of increasing suicide mortality in Poland: Undercounting amidst a hanging epidemic? // BMC Public Health. 12(644):1-9. 
Ivanova A.E., T.P. Sabgajda, V.G. Semenova, V.G. Zaporozhenko, E.V. Zemlyanova, S.Yu. Nikitina (2013). Faktory iskazheniya struktury prichin smerti trudosposobnogo naseleniya Rossii [Factors distorting structure of death causes in working population in Russia]. // «Social'nye aspekty zdorov'ya naseleniya» [Social Aspects of Population Health] ehlektronnyj nauchnyj zhurnal. 4(32). URL:

http://vestnik.mednet.ru/content/view/491/30/lang,ru/ (data accessed: 20.03.2014).

Ivanova A., V. Semenova, E. Dubrovina (2004). Marginalizacija rossijskoj smertnosti (Marginalisation of Russian mortality) // Demoscope Weekly. №181-182. URL: http://demoscope.ru/weekly/2004/0181/tema01.php (data accessed: 13.11.2014).

Kapusta N.D., U.S. Tran, I.R. Rockett, D. De Leo, C.P. Naylor, T. Niederkrotenthaler, M. Voracek, E. Etzersdorfer, G. Sonneck (2011). Declining autopsy rates and suicide misclassification: A cross-national analysis of 35 countries // Archives of General Psychiatry. 68(10): 1050-1057.

Kolmos L. (1987). Suicide in Scandinavia. An epidemiological analysis // Acta Psychiatrica Scandinavica. 76 (Suppl336): 11-16

Kvasha E.A., T.L. Kharkova (2011). Programmy, napravlennye na snizhenie smertnosti prinyaty. Kakovy ih rezul'taty? [Programs aimed to prevent premature mortality has started: what are their effects?] // Demoscope-Weekly. № 463 - 464, URL:

http://demoscope.ru/weekly/2011/0463/analit04.php\#_FN_4 (data accessed: 2.05.2014).

KZ SPb (1997). Prikaz Komiteta po zdravoohraneniyu Administracii Sankt-Peterburga ot 18.03.1997 №98 «O vvedenii v dejstvie instruktivno-metodicheskih materialov po kodirovaniyu prichin smerti v medicinskoj dokumentacii»».

Meslé F., J. Vallin, V. Hertrich, E. Andreev, V. Shkolnikov (2003). Causes of death in Russia: assessing trends since the 1950s // European Population Conference «Population of Central and Eastern Europe. Challenges and Opportunities» / Irena E. Kotowska and Janina Józwiak, eds. Statistical Publishing Establishment. Warsaw: 389-414. URL: http://demoscope.ru/weekly/knigi/epc.php (data accessed: 11.07.2014).

Meslé F., V. Shkolnikov, V. Hertrich, J. Vallin (1996). Sovremennye tendencii smertnosti po prichinam smerti v Rossii, 1965-1994. [Recent trends in mortality by cause of death in Russia, 1965-1994]. // Donnes de statistiques. Paris: INED, №2 http://demoscope.ru/weekly/knigi/shkol/shkol.html (data accessed: 26.09.2013).

MZ RF (1996). Prikaz Ministerstva zdravoohraneniya Rossijskoj federacii №398 ot 04.12.1996 «O kodirovanii (shifrovke) prichin smerti v medicinskoj dokumentacii».

MZ RF (1998). Prikaz Ministerstva zdravoohraneniya Rossijskoj Federacii ot 07.08.1998 №241 "O sovershenstvovanii medicinskoj dokumentacii, udostoveryayushchej sluchai rozhdeniya i smerti, v svyazi s perekhodom na MKB-H».

MZSR (2009). Pis'mo Ministerstva zdravoohraneniya i social'nogo razvitiya RF ot 19.01.09 №14-6/10/2-178 «O poryadke vydachi i zapolneniya medicinskih svidetel'stv o rozhdenii i smerti»

MZSR (2010a). Prikaz Ministerstva zdravoohraneniya i social'nogo razvitiya RF ot 12.05.10 №346n "Ob utverzhdenii Poryadka organizacii i proizvodstva sudebno-medicinskih ehkspertiz $\mathrm{v}$ gosudarstvennyh sudebno-ehkspertnyh issledovanij v byuro sudebnomedicinskoj ehkspertizy»

MZSR (2010b). Prikaz Ministerstva zdravoohraneniya i social'nogo razvitiya ot 04.06.10 №423n "O priznanii utrativshim silu Prikaza Ministerstva zdravoohraneniya Rossijskoj Federacii ot 
24 aprelya 2003 g. №161 "Ob utverzhdenii Instrukcii po organizacii i proizvodstvu ehkspertnyh issledovanij v byuro sudebno-medicinskoj ehkspertizy".

Nikitina S.Yu., G.M. Kozeeva (2006). Sovershenstvovanie statistiki smertnosti ot alkogolizma [Improvement of statistics of mortality from dipsomania.] // Voprosy statistiki [Statistical Studies]. №11: 21-23.

O'Carroll P.W. (1989).A consideration of the validity and reliability of suicide mortality data // Suicide Life Threat Behavior. 19(1): 1-16.

Parks S.E., L.L. Johnson, D.D. McDaniel, M. Gladden (2014). Surveillance for violent deathsnational violent death reporting system, 16 states, 2010 // MMWR Surveillance Summaries. 63): $1-33$.

Porodenko V.A., V.V. Chernobaj (1999). Sovremennye tendencii v dinamike nasil'stvennoj i nenasil'stvennoj, smerti i problemy ih ucheta [Modern trends in dynamics of violent and nonviolent deaths and an issue of their account // Sudebno-medicinskaya ehkspertiza [Forensicmedical expertise]. № 5: 20-23.

Pridemore W.A. (2003). Measuring homicide in Russia: a comparison of estimates from the crime and vital statistics reporting systems // Social Science \& Medicine. 57(8): 1343-1354.

Rockett I.R., N.D. Kapusta, R. Bhandari (2011). Suicide misclassification in an international context: revisitation and update // Suicidology Online. 2: 48-61.

Rukovodstvo po kodirovaniyu prichin smerti [Guide to coding of death causes]. M.: CNIIOIZ, 2008. URL: www.mednet.ru/images/stories/files/statistika/organizacionnometodicheskie_materialy/Rukovodstvo_po_kodirovaniyu_prichin_smerti.pdf (data accessed: 26.09.2013).

Ruzicka Lado T. (1996). A note on suicide I Russia, 1963-1993 // Journal of the Australian Population Association. Vol.16 (2), 1996: 187-193.

Semenova V.G., N.S. Gavrilova, G.N. Evdokushkina, L.A. Gavrilov (2004). Kachestvo medikostatisticheskih dannyh kak problema sovremennogo rossijskogo zdravoohraneniya [Quality of medical statistics as an issue of contemporary Russian public health] // Obshchestvennoe zdorov'e i profilaktika zabolevanij [Public health and diseases prevention]. (2): 11-19.

Semenova V.G., O.I. Antonova (2007). Dostovernost' statistiki smertnosti (na primere smertnosti ot travm I otravlenij v Moskve) [Reliability of mortality statistics (on example of injuries and poisoning in Moscow)] // Social'nye aspekty zdorov'ja naselenija [Social aspects of population health].№2. URL: http://vestnik.mednet.ru/content/view/28/30/ (data accessed: 26.09.2013).

Shurygina I. (2013). Smertnost rossijskih detej ot vneshnih prichin [Mortality of Russian children due to external causes) // Demoscope Weekly. №537-538 URL: http://www.demoscope.ru/weekly/2013/0537/demoscope537.pdf (data accessed: 17.10.2014).

Sorenson S.B., H. Shen, J.F. Kraus (1997a). Coroner-Reviewed Infant and Toddler Deaths: Many «Undetermineds» Resemble Homicides // Evaluation Review. 21(1): 58-76.

Sorenson S.B., H. Shen, J.F. Kraus (1997b). Undetermined Manner of Death: A Comparison With Unintentional Injury, Suicide, and Homicide Death // Evaluation Review. 21(1): 43-57.

Tøllefsen I.M., E. Hem, Øivind Ekeberg (2012). The reliability of suicide statistics: a systematic review // BMC Psychiatry. 12(9): 1-11. 
Väli M., K. Lang, R. Soonets, M. Talumäe, A.M. Grjibovski Childhood deaths from external causes in Estonia, 2001-2005 // BMC Public Health. 2007. 7(1): 158.

Värnik P., M. Sisask, A. Värnik, A. Yur’Yev, K. Kolves, L. Leppik, A. Nemtsov, D. Wasserman (2010). Massive increase in injury deaths of undetermined intent in ex-USSR Baltic and Slavic countries: Hidden suicides? // Scandinavian Journal of Public Health. 38(4): 395-403.

Värnik, P., M. Sisask, A. Värnik, E. Arensman, C.V. Audenhove, C.M. van der Feltz-Cornelis, U.Hegerl (2012). Validity of suicide statistics in Europe in relation to undetermined deaths: developing the 2-20 benchmark // Injury Prevention. 18(5): 321-325.

Wasserman D., A. Värnik (1998). Reliability of statistics on violent death and suicide in the former USSR, 1970-1990 // Acta Psychiatrica Scandinavica. 98(S394): 34-41.

VOZ (2003). Mezhdunarodnaya statisticheskaya klassifikaciya boleznej i problem, svyazannyh so zdorov'em: MKB-10 [International Statistical Classification of Diseases and Related Health Problems 10th Revision]. V 3-h tomah. Tom 2. M.: Medicina.

Whitt H.P. (2006). Where Did the Bodies Go? The Social Construction of Suicide Data, New York City, 1976-1992 // Sociological Inquiry. 76(2): 167-186.

WHO (2014). WHO methods and data sources for country-level causes of death 2000-2012 / Global Health Estimates Technical Paper WHO/HIS/HSI/GHE/2014.7

WHO mortality database. URL: http://www.who.int/healthinfo/mortality_data/en/ (data accessed: 30.01.2014). 